Universidad de Lima

Facultad de Comunicación

Carrera de Comunicación

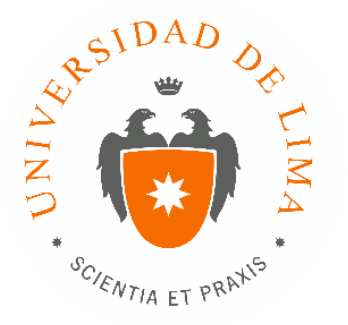

\title{
CERVEZA JETZT
}

Trabajo de suficiencia profesional para optar el Título Profesional de Licenciado en Comunicación

\section{Mayra Alessandra Chipana Zaga \\ Código 20121623}

Lima - Perú

Setiembre del 2018 


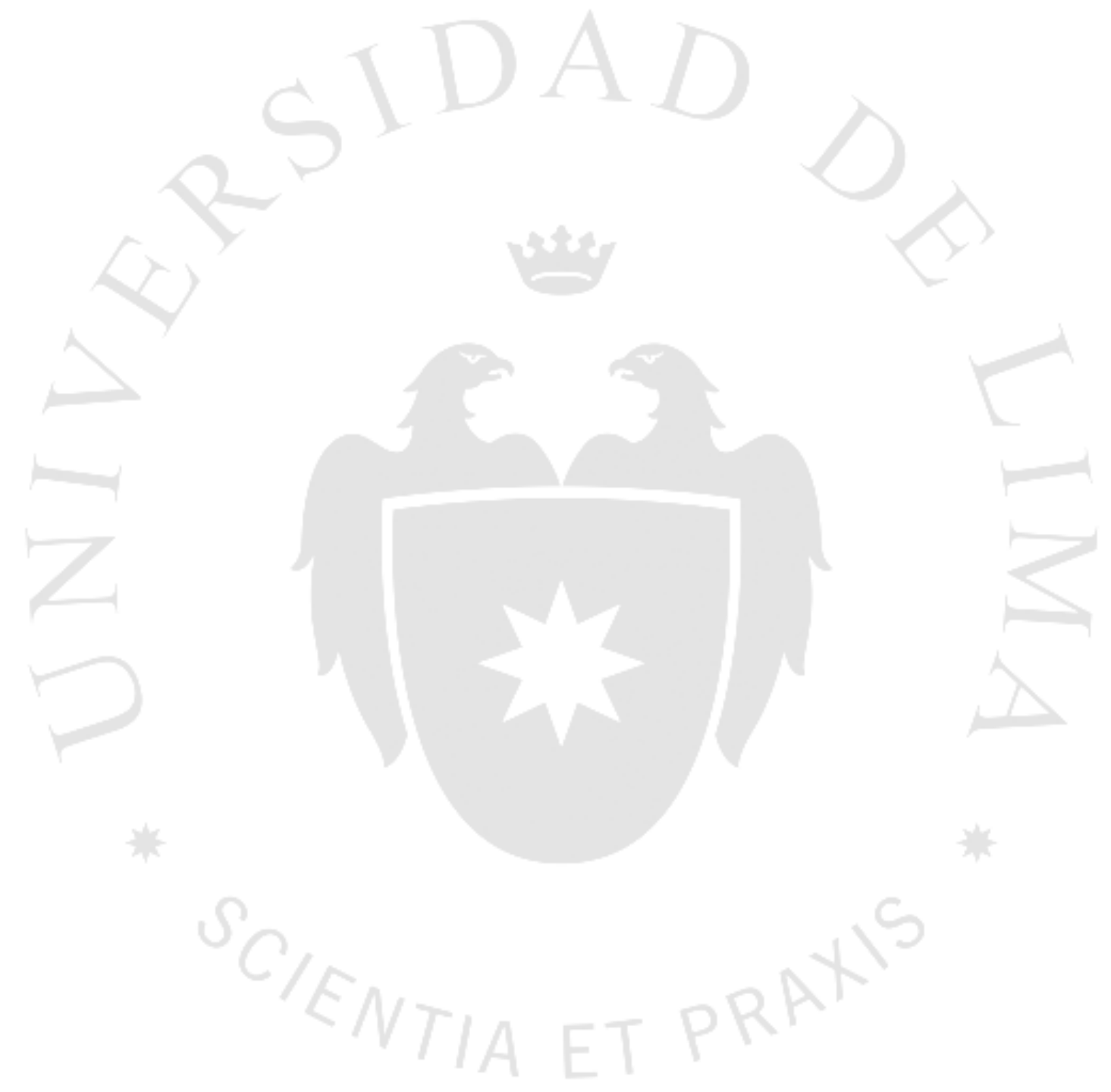




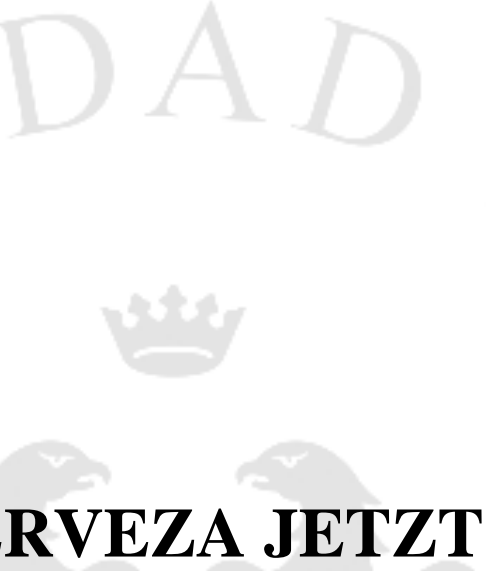

CERVEZA JETZT 


\section{TABLA DE CONTENIDO}

Introducción

Capítulo I: Análisis Estratégico

1.1 Definición del Producto

1.2 Análisis Externo

1.2.1 Mercado de cerveza

1.2.2 Competencia

Capítulo II: Campaña de Comunicación

1.1 Objetivos de comunicación

1.1.1 Posicionamiento deseado

1.1.2 Público objetivo

1.1.3 Insights

1.1.4 Promesa - Ventaja diferencial

1.1.5 Razón para creer

1.1.6 Idea de Marca

1.1.7 Valores

1.1.8 Personalidad de Marca

1.2 Imagen de Marca

1.2.1 Naming

1.2.2 Logotipo

1.3 Estrategia Creativa

1.3.1 Concepto creativo

1.3.2 Idea creativa

1.3.3 Aplicación en el empaque

1.4 Estrategia de Comunicaciones

1.4.1 Televisión

1.4.2 Radio

1.4.3 Impreso

34

1.4.4 BTL

36

1.4.5 Digital

38

Conclusiones

43

Recomendaciones

44

Referencias 


\section{INTRODUCCIÓN}

El presente trabajo muestra una propuesta de lanzamiento de la marca de Cerveza "Jetzt" sin alcohol en el mercado peruano, destacando sus beneficios de seguir disfrutando de su calidad y sabor, evitando los inconvenientes que produce el alcohol. Para ello se trabajó en definir el concepto de la marca basada en los Insights hallados, para poner en efecto las estrategias lanzamiento de la marca, seguido de crear el packaging que comparta este mismo espíritu y piezas gráficas que sean resonante en medios tradicionales y digitales. 


\section{CAPÍTULO I: ANÁLISIS ESTRATÉGICO}

\subsection{Definición del Producto}

La cerveza es una de las bebidas universales más antiguas y más importante en casi todas las culturas; se desconoce con el lugar de origen con exactitud, pero existen evidencias de que fue en Sumeria (Mesopotania) por el 4.000 a.c donde reservaban la cosecha de cereales para su fabricación, fermentando al principio por casualidad para luego prepararlas en tinajas de agua. Esta civilización pasó a convertirse en el Imperio Babilónico quien llevó la fabricación de la cerveza a otro nivel, preparando más de 20 recetas de este mismo.

Su presencia no se limitó en Mesopotania; los egipcios también desarrollaron cerveza de una forma parecida y lo perfumaban con canela y frutos. En el mundo esta bebida surgía con otros nombres y particularidades propias de sus imperios, China por su parte mezclaba la cebada y trigo junto al arroz, utilizada para el culto de los muertos, llamado "Kiu"; por su parte los aztecas lo usaban para rezar a sus dioses. La popularidad de esta bebida evolucionó a lo que conocemos, con infinidad de variantes que se producen en todo el mundo, con y sin alcohol. ${ }^{1}$

La cerveza sin alcohol es uno de los resultados de la fabricación de cervezas de baja fermentación implementado desde 1870, creadas con un menor contenido alcohólico, más suave y refrescante. Su proceso de producción cambió la manera de fabricar esta industria, con mayor requerimiento de capital y tecnología ${ }^{2}$.

Las de baja fermentación son conocidas como lager que varían de acuerdo al tiempo de fermentación en sus colores, rubias más claras, doradas o tostadas. La temperatura recomendable para cervezas claras y de baja fermentación, como la cero alcohol, a un 3,5 a $7.5^{\circ} \mathrm{C}$ para que siga refrescante y saciadora mientras se pueda disfrutar aún de su aroma y sabor ${ }^{3}$.

\footnotetext{
${ }^{1}$ Referencia: Velasco, Débora 2015, "Hábitos de Consumo sobre la Cerveza".

Pilla,S. Vinci, G. 2012 "Cervezas de todo el Mundo".

2 García Barber, X. 2014 "La cerveza en España: Orígenes e implantación de la industria cervecera"

${ }^{3}$ Temperaturas de servicio adecuadas para cada tipo de cerveza. (2018, 15 junio). Recuperado 2 septiembre, 2018, de https://www.thebeertimes.com/temperaturas-de-servicio-adecuadas-para-cada-tipo-de-cerveza/
} 


\subsection{Análisis externo}

Se realiza un análisis externo para conocer y comprender el mercado de Cerveza en el Perú y la competencia del rubro de cervezas sin alcohol.

\subsubsection{Mercado de Cerveza}

Los principales hallazgos del mercado cervecero:

- Backus y Johnston ejerce el liderazgo en la industria cervecera con un $99 \%$ de participación con su portafolio de productos. En el 2016 SAB Miller fue comprada por Ab Inbev, consolidando a Backus su posición dominante. El 1\% del mercado lo deja para la fabricación artesanal, según el anuario Perú: The Top 10.000 Companies 2017. La compañía es dueña de marcas emblemáticas como Cristal, Pilsen Callao o Cusqueña. En total sumaba 12 marcas de cervezas en el 2017, pero con la fusión de SABMiller y AB Inbev incorporó otras tres a su portafolio: Corona, Budweiser y Stella Artois ${ }^{4}$.

- ISC es el Impuesto Selectivo de Consumo, según la SUNAT la finalidad de este impuesto es desincentivar el consumo de productos que generan externalidades negativas en el orden individual, social y medioambiental como lo son las bebidas alcohólicas, combustible y cigarrillos ${ }^{5}$.

Este impuesto, desde junio del 2018 por un decreto supremo del gobierno, aumentó de lo que anteriormente pagaban los proveedores de productos alcohólicos. Este impuesto se calcula de dos formas, por monto fijo que es un monto en soles por litro y por monto al valor que es un \% de la suma importada, sea la cifra más alta de estas la cual se finalmente se paga. Para el caso de bebidas de 0-6 \% de alcohol el impuesto específico por litro es de S/ 1.25 o un impuesto en paralelo para este tipo de bebida que es el PVP

${ }^{4}$ Redacción EC. (2017, 5 agosto). Backus y las marcas con las que domina el mercado cervecero en el Perú [FOTOS]. Recuperado 2 septiembre, 2018, de https://elcomercio.pe/economia/backus-marcas-domina-mercadocervecero-peru-fotos-noticia-447675? foto $=2$

5 SUNAT. (s.f.). Concepto del Impuesto Selectivo al Consumo. Recuperado de http://orientacion.sunat.gob.pe/index.php/empresas-menu/impuesto-general-a-las-ventas-y-selectivo-alconsumo/impuesto-selectivo-al-consumo-empresas 
(Precio de Venta al Público) subiendo del 30\% al 35\% sobre el precio de venta sugerido ${ }^{6}$.

ISC Bebidas Alcohólicas

\begin{tabular}{|c|c|c|c|}
\hline \multicolumn{4}{|c|}{ Anterior } \\
\hline \multirow{2}{*}{$\begin{array}{l}\text { Contenido de } \\
\text { alcohol }\end{array}$} & \multicolumn{3}{|c|}{ Sistema Mixto } \\
\hline & $\begin{array}{l}\text { Especifico } \\
\text { S/ por litro }\end{array}$ & Al Valor & Al Valor PVP \\
\hline $0-6$ & 1,25 & & $30 \%$ \\
\hline $6-20$ & 2,50 & $25 \%$ & \\
\hline $20+$ & 3,40 & $25 \%$ & \\
\hline \multicolumn{4}{|c|}{ Vigente } \\
\hline \multirow{2}{*}{$\begin{array}{l}\text { Contenido de } \\
\text { alcohol }\end{array}$} & \multicolumn{3}{|c|}{ Sistema Mixto } \\
\hline & $\begin{array}{l}\text { Específico } \\
\text { S/ por litro }\end{array}$ & Al Valor & Al Valor PVP \\
\hline $0-6$ & 1,25 & & $35 \%$ \\
\hline $6-12$ & 1,70 & $20 \%$ & \\
\hline $12-20$ & 2,70 & $30 \%$ & \\
\hline $20+$ & 3,40 & $40 \%$ & \\
\hline
\end{tabular}

Fuente: El Peruano

- Las Provincias del País que más se venden bebidas alcohólicas son Junín, Puno y Piura, principalmente Junin y Puno, como en otras provincias de la sierra, realizan celebraciones denominadas Fiestas Patronales, en el cual se realiza alto consumo de alcohol. Piura, propio de las provincias del norte, gozan de un clima caluroso durante el año que beneficia la demanda de cerveza ${ }^{7}$. A diferencia de la Sierra, como hallazgo, es que son dos momentos distintos de celebración y la finalidad de las fiestas patronales son mucho más culturales y el consumo en cambio el Norte puede ser más adaptable ya que puede crear motivos o momentos para su consumo ya que el factor es más climático.

\footnotetext{
${ }^{6}$ Chávez, L. (2018, 11 mayo). ¿Cómo afectará el alza del ISC a las bebidas alcohólicas? Recuperado de https://elcomercio.pe/economia/peru/impuesto-selectivo-consumo-afectara-alza-isc-bebidas-alcoholicas-noticia-519077

${ }^{7}$ Redacción LR. (2011, 3 febrero). Junín, Puno y Piura consumen más cerveza. Recuperado de https://larepublica.pe/archivo/516554-junin-puno-y-piura-consumen-mas-cerveza
} 
1.2.1.1 Legal: Según el Decreto Legislativo $\mathrm{N}^{\circ} 1194$ que regula los procesos en casos de flagrancia, en caso de realizar la prueba de dosaje etílico tenga como resultado en la sangre un valor más de 0.5 gramos de alcohol por litro de sangre, es considerado un delito "Peligro Común". Es decir, el beber 3 vasos de cerveza con $\%$ de alcohol o 2 copas de vino puede ser una falta muy grave. La pena por manejar ebrio es una multa de 1975 soles y la retención de tu permiso de manejo como suspensión de 3 años del brevete

\begin{tabular}{|c|c|c|c|c|c|c|}
\hline CÓDIGO & INFRACCIÓN & CALIFICACIÓN & SANCIÓN & $\begin{array}{c}\text { PUNTOS } \\
\text { QUE } \\
\text { ACUMULA }\end{array}$ & $\begin{array}{c}\text { MEDIDA } \\
\text { PREVENTIVA }\end{array}$ & $\begin{array}{c}\text { RESPONS. } \\
\text { SOLIDARIA DEL } \\
\text { PROPIETARIO }\end{array}$ \\
\hline \multicolumn{7}{|c|}{ M. MUY GRAVES } \\
\hline M.1 & $\begin{array}{l}\text { Conducir con presencia de alcohol en la } \\
\text { sangre en proporción mayor a lo } \\
\text { previsto en el Código Penal, o bajo los } \\
\text { efectos de estupefacientes, narcóticos } \\
\text { y/o alucinógenos comprobado con el } \\
\text { examen respectivo o por negarse al } \\
\text { mismo y que haya participado en un } \\
\text { accidente de tránsito. }\end{array}$ & Muy grave & $\begin{array}{c}100 \% \text { de la UIT, } \\
\text { cancelación de la } \\
\text { licencia de conducir e } \\
\text { inhabilitación definitiva } \\
\text { para obtener una } \\
\text { licencia }\end{array}$ & & $\begin{array}{l}\text { Internamiento } \\
\text { del vehículo y } \\
\text { retención de } \\
\text { la licencia de } \\
\text { conducir }\end{array}$ & SI \\
\hline M.2 & $\begin{array}{l}\text { Conducir con presencia de alcohol en la } \\
\text { sangre en proporción mayor a lo } \\
\text { previsto en el Código Penal, bajo los } \\
\text { efectos de estupefacientes, narcóticos } \\
\text { y/o alucinógenos comprobada con el } \\
\text { examen respectivo o por negarse al }\end{array}$ & Muy grave & $\begin{array}{c}50 \% \text { de la uIT, } \\
\text { suspensión de la } \\
\text { licencia de conducir por } \\
\text { tres ( } 3 \text { ) años }\end{array}$ & & $\begin{array}{l}\text { Internamiento } \\
\text { del vehículo y } \\
\text { retención de } \\
\text { la licencia de } \\
\text { conducir }\end{array}$ & SI \\
\hline
\end{tabular}

Fuente: SUTRAN ${ }^{8}$

En cuanto al artículo 7 de la Ley que regula la comercialización, consumo y publicidad de Bebidas alcohólicas, se indica que el rotulado o empaquetado de productos no debe ser menor al 10\% del área total del envase.

\subsubsection{Competencia}

Se presentará los principales hallazgos de la competencia en cuanto a participación de mercado, valoración de marca y mapeo de elementos gráficos destacados.

${ }^{8}$ SUTRAN. (s.f.). Reglamento nacional de transito | Sutran - Superintendencia de Transporte Terrestre de Personas, Carga y Mercancías. Recuperado 8 septiembre, 2018, de http://www.sutran.gob.pe/reglamento-nacional-de-transito/ 
- Según un estudio del 2015 realizado por la consultora CCR, señala la participación de mercado es liderado por la Cerveza Cristal, seguida por Pilsen Callao y Pilsen Trujillo9.

La cerveza cristal, la cerveza del Perú, es líder de la categoría a nivel nacional y es uno de los embajadores de la marca Perú, fue fundada en 1922 y es actualmente la marca estrella de Backus. La cerveza Pilsen Callao, la cerveza de la verdadera amistad, fue fundada en 1863 y por ser la primera cerveza en el país es donde radica el motivo de su color verde, el tipo es Lager que es una cerveza ligera y aromática. Por último, Pilsen Trujillo fue lanzada en 1920, y parte de su estrategia de mercado regional es evidenciar el orgullo trujillano y sus costumbres.

\section{PARTICIPACIÓN DE MERCADO EN VOLUMEN POR MARCAS}

\begin{tabular}{|llcl|}
\hline Cristal & Pilsen Callao & Pilsen Trujillo & Barena \\
Cusqueña & Cusqueña variedades & Arequipeña & Brahma \\
San Juan & Lowenbrau & Budweiser & Otros \\
\hline
\end{tabular}

\section{$\begin{array}{llllllll}38.2 & 38.0 & 37.3 & 36.8 & 35.8 & 35.5 & 35.4 & 35.4\end{array}$ \\ $\begin{array}{llllllll}29.7 & 30.3 & 31.0 & 31.3 & 31.9 & 32.2 & 32.0 & 32.1\end{array}$}

$\begin{array}{llllllll}9.4 & 8.9 & 9.0 & 9.0 & 9.0 & 8.8 & 9.1 & 8.9\end{array}$

Feb Mar Abr May Jun Jul Ago Set

FUENTE: Auditoría de CCR

Fuente: Auditoria de CRR 2015

- Cristal y Pilsen lideran los dos primeros lugares del ranking del BrandZ Top 20 del 2018 que elabora la agencia Kantar Millward Brown valorando

${ }^{9}$ Redacción Gestión. (2015, 15 octubre). Venta de SABMiller abre espacio para aumento de precios y nuevas marcas. Recuperado de https:/gestion.pe/economia/empresas/venta-sabmiller-abre-espacioaumento-precios-nuevas-marcas-102493 
factores de las marcas como su capacidad de generar influencia, innovación, enfoque de experiencias, cultura y propósito alineado a la estrategia del negocio ${ }^{10}$. Ambas marcas cerveceras realizaron un granesfuerzo en llegar al corazón del consumidor y exaltar la tradición de celebración, junto a un contexto deportivo positivo.

- Sin y 0 alcohol: En el Perú encontramos en supermercados seleccionados (Wong, Plaza Vea, Vivanda, Tottus, Candy) 3 productos con $0 \%$ alcohol, desprovista totalmente de la fermentación, y SIN alcohol (que contiene entre 0,4 y $0.6 \%$ de alcohol).

El primero es Erdinger, una cerveza importada desde Alemania , cuenta con un mensaje destacado y promesa de marca de "Alcohol free". Es la primera cerveza de trigo sin alcohol del mundo. Con respeto a esta marca, este tipo de cerveza destaca que es Lager, fina y refrescante, y tiene un $0.4 \%$ de alcohol por litro
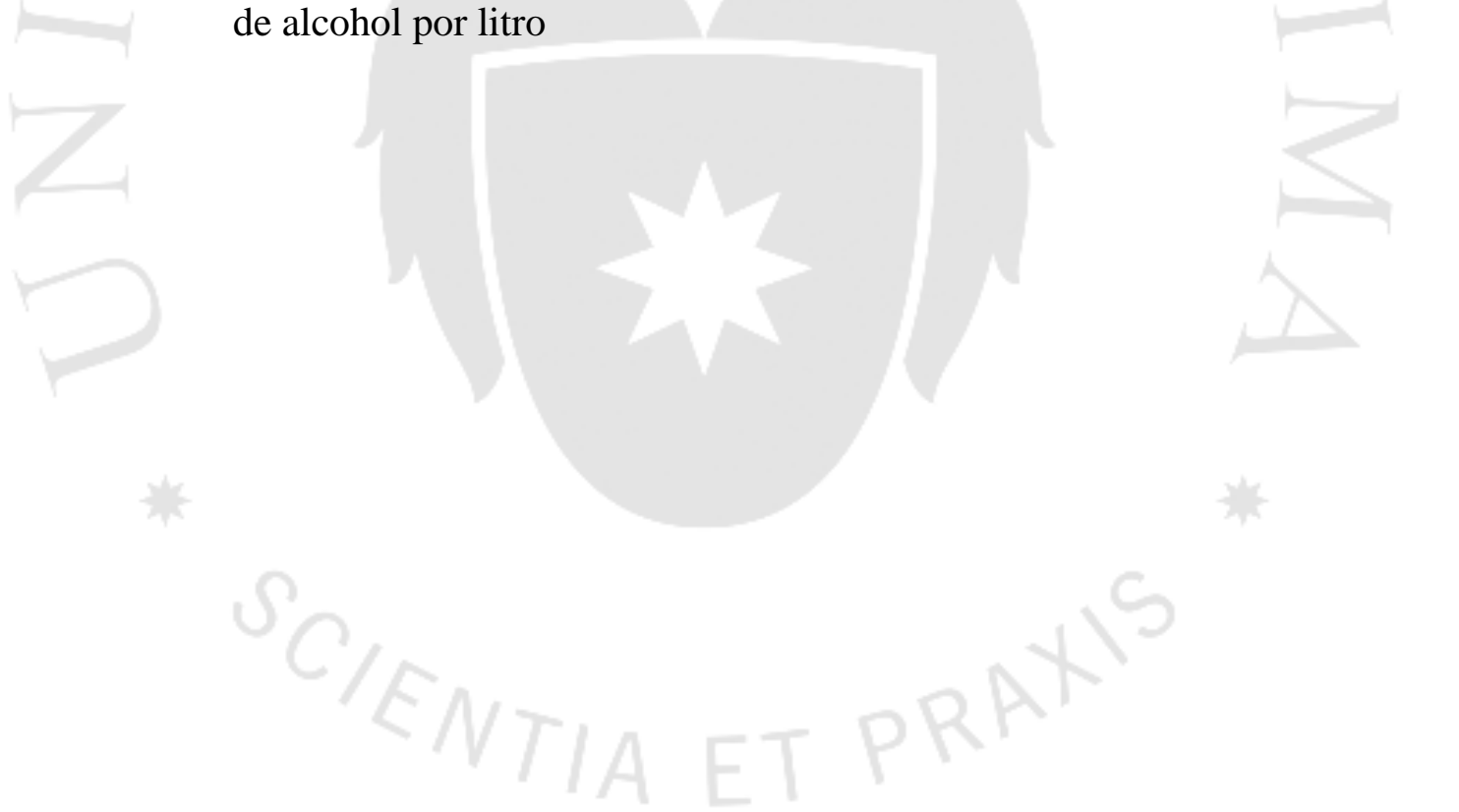

${ }^{10}$ Temperaturas de servicio adecuadas para cada tipo de cerveza. (2018, 15 junio). Recuperado 2 septiembre, 2018, de https://www.thebeertimes.com/temperaturas-de-servicio-adecuadas-para-cada-tipo-decerveza/ 

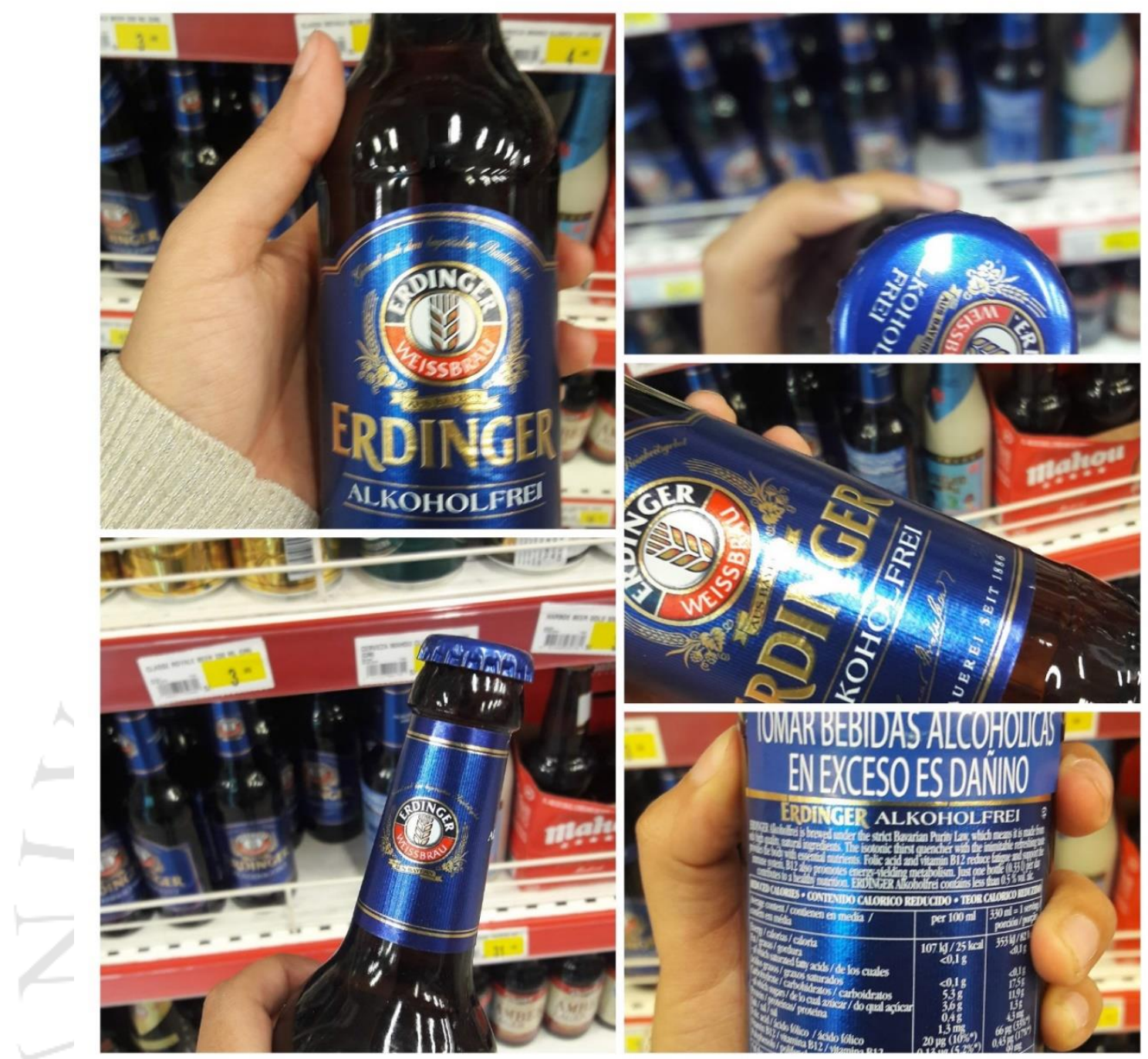

Fotografía: Mayra Chipana Zaga

Mahour Sin es una cerveza importada desde Madrid, su sabor es el mismo de la línea Mahou ya que contiene agua, malta de cebada, lúpulo y levadura, con ello generan el producto con un mínimo contenido de alcohol que es de $1 \%$ por litro de alcohol. 

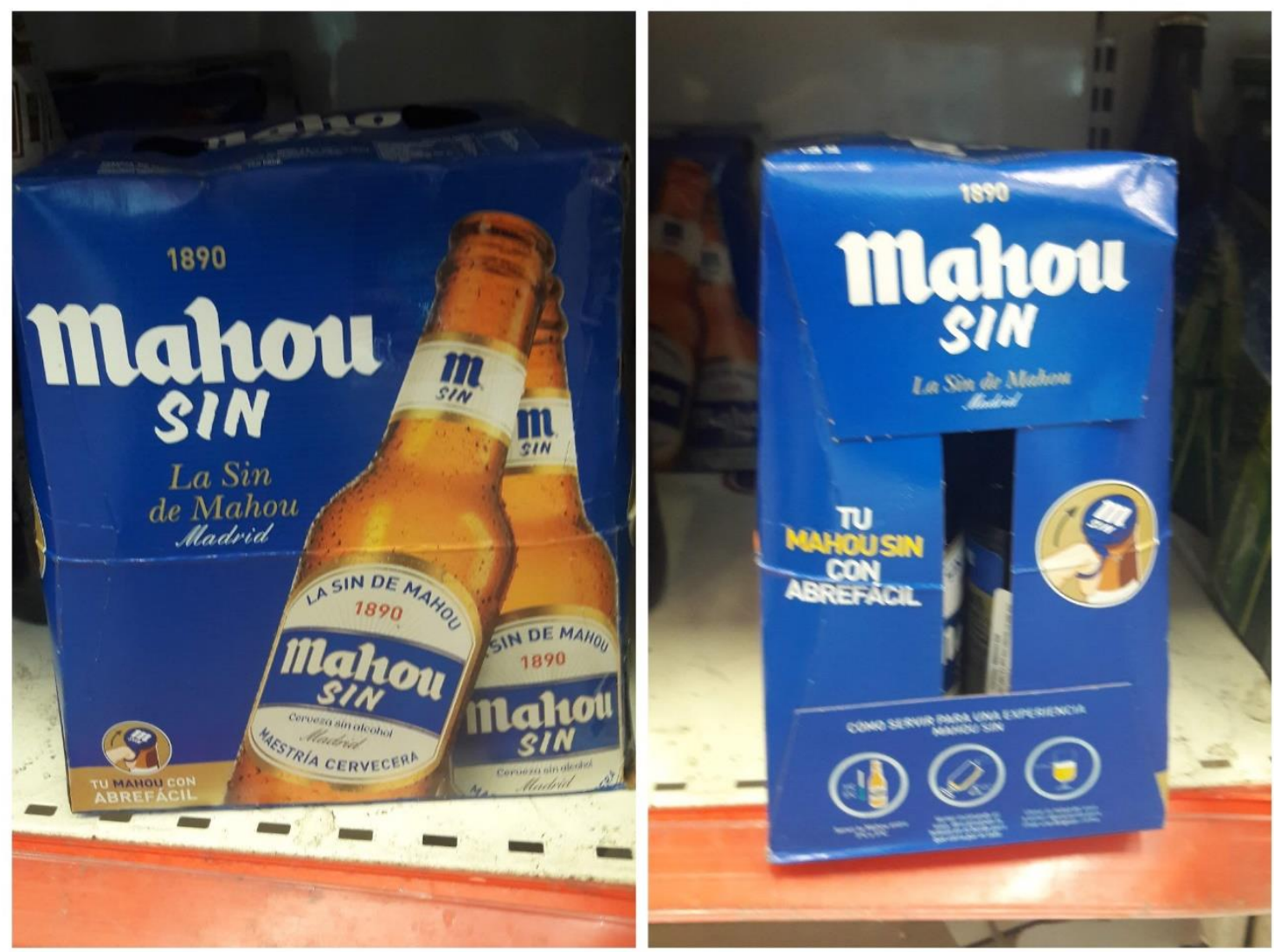

Fotografía: Mayra Chipana Zaga

Por último, Bitburger Drive 0,0\% de alcohol, es una cerveza rubia tipo pilsener, con una atenuación de los sabores dulces procedente de la malta y cuenta como parte de la promesa de la marca que cuentas con la posibilidad de seguir manejando, destacando más este beneficio sobre los valores que compone la marca. Además, Bitburger es la bebida oficial de la Selección Alemana de Futbol.

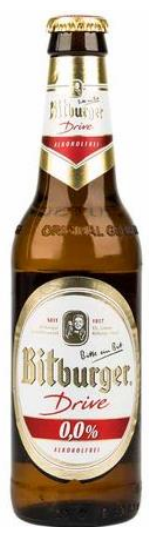

Figura 1: Imagen de Botella Bitburger Drive 
En cuento a precios de estas cervezas en el mercado nacional se presenta la siguiente tabla comparativa que se rescató de la visita de levantamiento de información en los principales supermercados

\begin{tabular}{|l|c|c|c|}
\hline \multicolumn{2}{|c|}{ Cerveza } & $\begin{array}{c}\text { Presentación } \\
\text { de } 330 \mathrm{ml}\end{array}$ & $\begin{array}{c}\text { Presentación } \\
\text { de } 500 \mathrm{ml}\end{array}$ \\
\hline $\begin{array}{l}\text { Cerveza Erdinger Sin } \\
\text { Alcohol }\end{array}$ & S/ 9.50 & S/ 13.50 & - \\
\hline Cerveza Bitburger Drive & S/ 6.00 & - & - \\
\hline Cerveza Mahou & - & - & S/ 28.00 \\
\hline
\end{tabular}

Se encontró como hallazgo que la competencia de cerveza sin alcohol ninguna presenta su versión en lata ni en six pack de esta misma, más sí es una versión mucho más habitual la presentación de 330ml para el caso de Cerveza Erdinger Sin alcohol y Bitbuger drive 0,0. Para el caso de Mahou solo se encontró su versión en six pack de botella, en el supermercado Wong, sin embargo, no guarda registro de esta cerveza importada dentro de su catálogo en línea.

\subsubsection{Mapeo de la Competencia}

- Formas básicas: Como parte del análisis estratégico de la competencia, se realiza un mapeo de las formas básicas del logotipo de la competencia con 4 atributos: moderno, tradicional, simple y complejo 


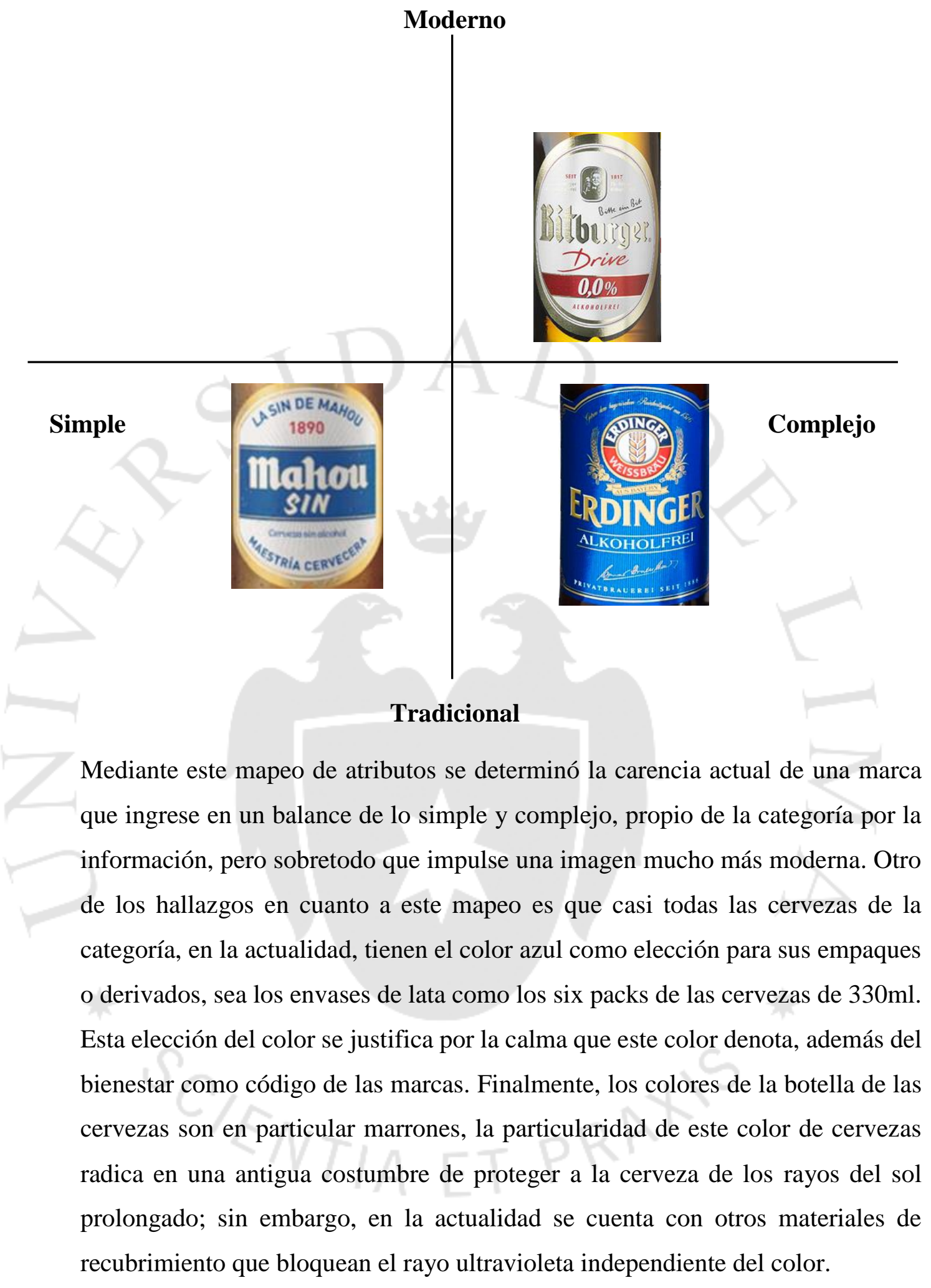




\section{CAPÍTULO II: CAMPAÑA DE COMUNICACIÓN}

\subsection{Objetivos de comunicación}

- Introducir a la marca Jetzt cero al mercado de cervezas que no contienen alcohol generando "Brand Awareness"

- Destacar los atributos diferenciales como parte de la propuesta de valor de la marca - Generar visibilidad y atracción en los puntos de venta con mensajes oportunos de la marca.

\subsubsection{Posicionamiento deseado}

Que la cerveza "Jetzt" cero es la mejor alternativa del joven peruano que quiere disfrutar del gran sabor, frescura y calidad de su cerveza lager sin preocupaciones, porque no contiene alcohol y cuenta con baja cantidad de calorías por lo que puedes aprovechar cada instante del día para beberlo sin reproches.

\subsubsection{Público objetivo}

El grupo objetivo primario acotado son hombres y mujeres entre 21 - 35 años de edad de nivel socioeconómico A y B de Lima y principales ciudades de la Costa del Perú. Según Ipsos apoyo (Perfil del adulto joven peruano 2018) podemos rescatar los siguientes datos:

- $\quad$ El 3\% de los adultos jóvenes pertenecen al nivel socioeconómico A; el 17\% pertenecen al B; por lo tanto, nuestro enfoque es del $20 \%$ de este sector.

- El $40 \%$ gastan su dinero en alimentación, comida y víveres.

- $55 \%$ ven televisión convencional para entretenerse en casa, mientras que $32 \%$ chatea por redes sociales y el $20 \%$ escucha música por app. Las actividades relacionadas a lo digital son predominantes en los NSE AB, siendo parte de redes sociales como Facebook, WhatsApp e Instagram como principales. La mayor parte de este target, el $85 \%$, son digitales y se 
conectan en promedio unas 6 veces por semana. Esto responde al pedido constante de renovarse y estar en tendencia con las novedades digitales.

- Según los hábitos y actitudes a los medios tradicionales se cuenta con información que el 77\% de limeños ven televisión en una frecuencia diaria, con mayor llegada de $54 \%$ hacia los noticieros o programas informativos, seguido por películas y deportivos.

- El horario habitual de mayor consumo televisivo es de 8:00 pm a 10:00 pm en el caso de ser diario ya que se realiza en el hogar

- América TV es el canal de señal abierta más visto por los televidentes limeños, seguida por latina con un 39\% en el NSE A y en B de un 55\%

- Nuevos medios como Netflix solo una cuarta parte de jóvenes adultos lo usan, mientras que Spotify lo tiene un $18 \%$ de ellos.

- Mientras que el entretenimiento fuera de casa radica más en un 49\% salir a comer, $28 \%$ ir a casa de amigos o familiares y un $9 \%$ salir a tomar tragos.

- En cuanto a Radio, el hábito de su consumo es de escuchar 3 a 4 veces a la semana y entre sus principales motivaciones está el sentirse relajado, acompañado y entretenido.

- Además, según el Perfil del usuario de redes sociales 2018, afirman que uno de cada cinco usuario de redes sociales sigue a un influencer y la mitad de estos usuarios se han visto influenciados por su referencia.

- En Facebook, los usuarios de redes sociales, lo utilizan para la creación de contenido e interacción, siendo los más destacados el chatear, comenta, publica e interactuar con sus amigos leyendo muros. En cuanto a Instagram el $74 \%$ publica fotos y videos, mira publicaciones un $66 \%$ y $52 \%$ da me gusta, el usuario activo de esta red social son principalmente los de 25 a 35 años y de NSE AB con un $49 \%$

- En cuanto a diarios, el hábito de este medio tradicional ha bajado pero destacando en el NSE AB el Comercio, y siendo los días de mayor frecuencia los días Lunes, miércoles y viernes seguida por el jueves.

Así mismo se rescata los principales hallazgos de los cambios en la preferencia de los consumidores que modifican a la industria:

- Según la reciente publicación de Rabobank para Gestión centra su análisis en el consumidor que se está volviendo más educado y próspero, con respecto 
a lo que consume. El número de consumidores que buscan productos con bajo alcohol o no alcohólicos, está creciendo, y el interés en la categoría es mayor entre los consumidores más jóvenes ${ }^{11}$.

- El Global Monitor de Kantar Futures comprobó que un 78\% de los consumidores de cerveza tratan de cuidar salud, por lo que es una oportunidad de espacio en su consumo, debido a que es una tendencia en crecimiento el cuidado y bienestar, incluso en los hombres; sin embargo, muchos no quieren mostrar que beben este tipo de cerveza puesto que aún existe esta brecha de conocimiento sobre las particularidades de la reducción de ingesta de alcohol y estigma social para el consumo de alcohol.

\subsubsection{Insights}

Para lograr recopilar la mayor cantidad de apreciaciones se envió una encuesta vía WhatsApp a 10 personas del público objetivo para que sean respondidas a través de voice notes. Los principales hallazgos de las apreciaciones y significado emocionales sobre la cerveza:

- "No me imagino a qué sabe una cerveza sin alcohol, no las conozco"

• "Si tomara sin alcohol sería más por el sabor de la cerveza que el alcohol"

• "Podría tomarlo en cualquier momento quizás"

- "Quisiera disfrutar sin que me miren extraño por si tomo, sin culpa"

• "Si tú estás tomando solo ya te están tildando de borracha sin saber"

- "Al menos ya no pasaría malas noches e igual lo disfrutaría"

Como análisis de los comentarios recopilados se destaca el desconocimiento de las marcas que el día de hoy se encuentran en punto de venta a nivel nacional en los supermercados más destacados como Wong y Tottus, siendo una posibilidad de penetrar en el conocimiento como líder de la categoría y asociar el producto con la marca para una mejor recordación. Como segundo destacado se encuentra que las personas tendrían que probarlo para atreverse a consumirlo, ya que de primer alcance tienen que impulsarlos para

11 Gestión. (2018, 15 febrero). LOS CAMBIOS EN LAS PREFERENCIAS DE LOS CONSUMIDORES ESTAN MODIFICANDO LA INDUSTRIA DE BEBIDAS | Blogs | Gestión. Recuperado 9 septiembre, 2018, de https://gestion.pe/blog/vinospiscosymuchomas/2018/02/los-cambios-en-las-preferencias-de-los-consumidores-estanmodificando-la-industria-de-bebidas.html?ref=gesr 
generar la compra y práctica, el contenido del mensaje por enviar debe tener este espíritu de apertura de la curiosidad. Finalmente, como último destacado -y más importante- de lo rescatado es que las personas cuentan que el estigma de la cerveza es igual a licor de alta densidad y fermentación ligada a los excesos, se debe presentar este producto como disruptivo al modelo social creado acerca de este producto por darle otra cara, más virtuoso y de amplia apertura; es decir, se debe resaltar qué necesidades estamos supliendo como virtudes y particularidades, esta apertura de poder valorar y disfrutar los momentos con autonomía y confianza en estos momentos, comunes de beber o no, siendo este último una oportunidad de generar nueva forma de compra.

\subsubsection{Promesa - Ventaja diferencial}

La libertad de tomar y disfrutar de tu cerveza lager en el momento que quieras sin preocupaciones pues no cuenta con alcohol.

\subsubsection{Razones para creer}

- El proceso para la elaboración de la cerveza Jetzt cumple con la técnica de fermentación controlada para lograr eliminar el alcohol.

- Cuenta con sabor balanceado de dulce y amargo propio de las cervezas lager

- Para el bienestar y cuidado de la salud esta cerveza cuenta con menos calorías. Además de sustancias que ayudan como minerales, vitaminas y antioxidantes sin la preocupación de que exista exceso que perjudique.

- Su consumo es admisible para personas que deseen movilizarse manejando sin alguna regulación de tránsito que se incumpla. Así como altamente nutritivo para mujeres embarazadas.

- La marca se muestra fresca y atrevida, ya que nació para cambiar el modo de ver a la cerveza.

- Necesidades aterrizadas: Fisiológicas, de hidratación, ya que el producto es 95\% agua y fresco por la temperatura adecuada de su ambientación que es de $10^{\circ}$; Seguridad, de sentirse seguro, estable y confiado ante un producto que le brinda la certeza y compromiso de su elaboración 


\subsubsection{Idea de Marca}

Con la Cerveza Jetzt cero aprovecha el momento para hacer algo distinto.

\subsubsection{Fundamento de la Idea de Marca}

- El concepto de marca "Aprovecha el momento para hacer algo distinto" impulsa el consumo en cualquier circunstancia y de no dejar pasar la oportunidad de disfrutarlo, de animarse a realizar lo distinto a lo que siempre está acostumbrado o lo que externamente nos han inducido a pensar. Al no tener alcohol no debe existir preocupación, vergüenza y debe generar en el consumidor la confianza de una bebida de compañía que no esté relacionado con excesos. Es un llamado al accionar a que el día, la hora, o cualquier momento que gusten puede disfrutarlo.

\subsubsection{Valores}

- Integridad de garantizar la elaboración y calidad de una cerveza cero alcohol.

- Libertad y confianza entregada al consumidor para el disfrute de la cerveza cero alcohol

\subsubsection{Personalidad de la marca}

Alegre y desenfadada, al mismo tiempo demuestra calidad. 


\subsection{Imagen de Marca}

\subsubsection{Naming:}

La propuesta de nombre de la marca de cerveza, siguiendo los lineamientos del país de origen, se desarrolla en el idioma alemán, viendo como posibilidad que el nombre seleccionado cuente con propiedades acorde con el concepto seleccionado.

En el mapeo de particularidades nació Jetzt, que tiene significado como el ahora, el presente, en este momento, ahora mismo, hacerlo iya!, queriendo enviar ese mensaje de atreverte a hacer las cosas en el tiempo que debes, en ese momento cuando ingresas a esa encrucijada de hacerlo o no. Además de tener el aspecto positivo de ser un nombre corto, rescatando este aspecto sobre la competencia de cervezas importadas, y ser de fácil recordación que pueda llegar a tener la flexibilidad de ser distintiva y aun así guardar registro. Este naming se incluirá en los empaques al igual que el origen de la cerveza.

\subsubsection{Logotipo}

La cerveza Jetzt cero requería un logo que represente su personalidad moderna y alegre, que abarque sus aspectos diferenciales en el diseño, tipografía, colores y que esta misma estética se pueda desenvolver en el resto de materiales tangibles. Así mismo, la concepción del logotipo debe dar pie a que se presenta dentro de la categoría de cerveza en su imaginario y preconcepción.

\subsubsection{Concepto del Logotipo}

La idea de imagen para la realización del logotipo se basó en darle mayor porcentaje de espacio al nombre de la marca para generar mayor nivel de registro, además de mostrarse distinta a la categoría que tienen imágenes representativas de cerveza, lúpulo, cebada u otros elementos de una cerveza tradicional que descartamos para darle mayor compañía de elementos gráficos como son las líneas y combinación de colores. El color de fondo azul de la imagen ha sido seleccionado solo con el fin de brindar contraste ya que no es un determinante el color de fondo, sino de transparencia. 


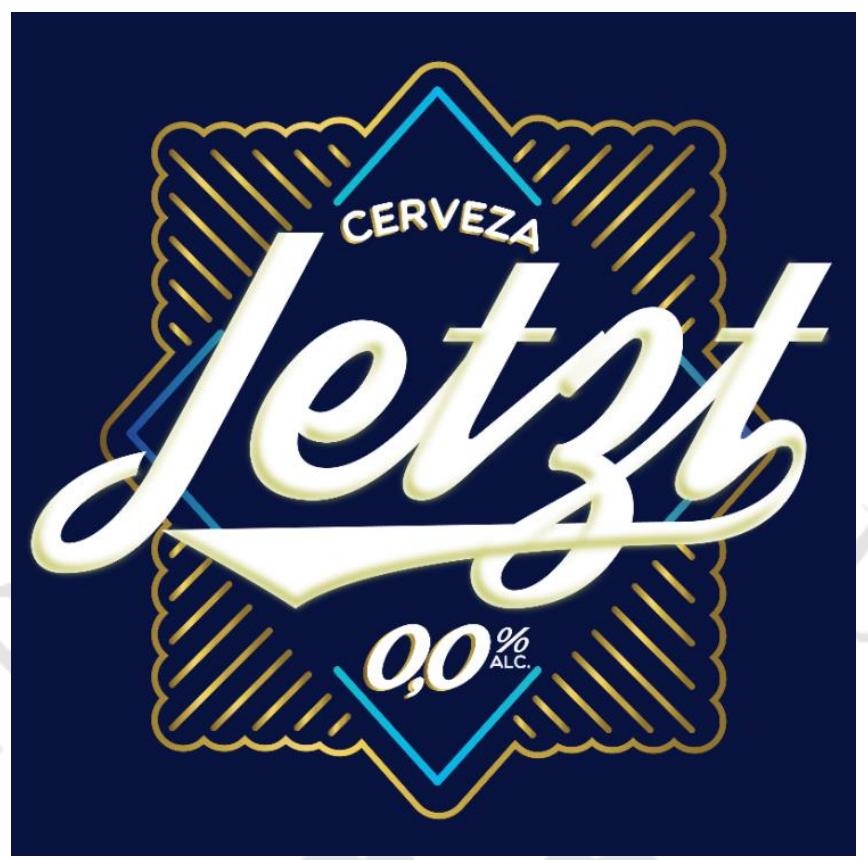

Las líneas gruesas que enmarcan el nombre denotan mayor impacto en la figura central y se muestran en un ángulo diagonal para generar un significado de dinamismo, potencia y fortaleza a comparación de un ángulo recto o horizontal, así mismo para que la figura no se muestre dispersa como líneas que señalen a otro destino, o fuera del central, se enmarcó bordeando la figura que proyectarían; para aumentar el llamativo y disrupción del dorado se incluyó un rombo de color azul degradado para contrastar y destacar el nombre. Jetzt, como nombre central, se desarrolló con trazos en cursiva propio de la letra script y para generar una variación en la dimensión se añadió unos bordes con desenfoque para crear un efecto de brillo y relieve.

\section{Tipografía:}

Se eligió la tipografía StreetWear para las palabras "Jetzt" por su formato de letras que transmiten calidad y creatividad, se generó algunos arreglos a la tipografía para una mejor lectura de las formas. Para las información complementaria como "cerveza" y “0,0\% alc.” Se utilizó el estilo san serif de la tipografía Multicolor, ya que son más de estilo comercial y legibles, ya que no son sobrecargadas y transmiten neutralidad, seguridad y modernidad. 


\subsubsection{Color}

Las gamas de colores están en tonos complementarios al azul, ya que es un color designado de la categoría de cervezas con bajo contenido de alcohol. Las líneas de las figuras de los bordes cuentan con un degradado de dorados y amarillos, como el color del contenido de la cerveza lager. El azul central de la figura del rombo es un degradado de la gama de azules.

Además de ser el color de la categoría, el azul denota tranquilidad, armonía, fuerza y simpatía, además de dar la sensación de frescura y ser de la categoría de colores fríos, en contraste a ello está la gama de colores cálidos como el mostaza, dorado y amarillo que transmiten alegría, jovial, afectivos e impulsivos. Denotas junto a las líneas los rayos que proyectan el dorado del sol, de la luz y calidez. ${ }^{12}$

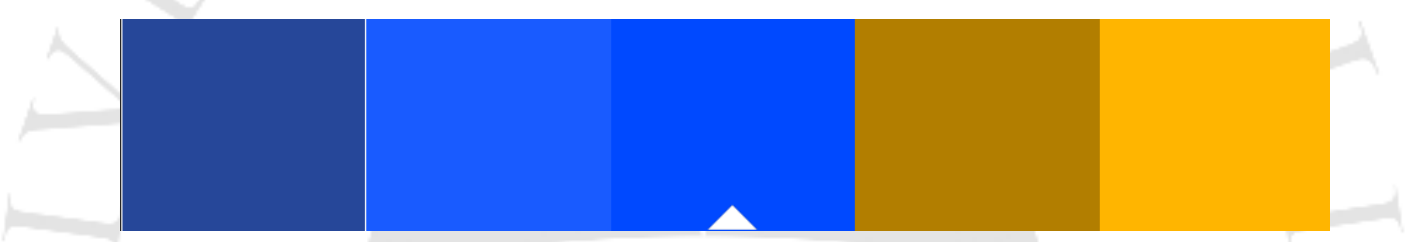

Colores complementarios del azul de Adobe Color

\subsubsection{Versiones blanco y negro:}

Estas versiones se utilizarán para realizar contrastes con imágenes o fondos. El logo no tiene un color entero de fondo predeterminado, pero en caso no se encontrase contraste que resalte el logo se utilizará sus versiones blanco y negro, con degradado.

\footnotetext{
${ }^{12}$ Heller, E. (2004). Psicología del color: cómo actúan los colores sobre los sentimientos y la razón.
} Barcelona, España: Gustavo Gili. 

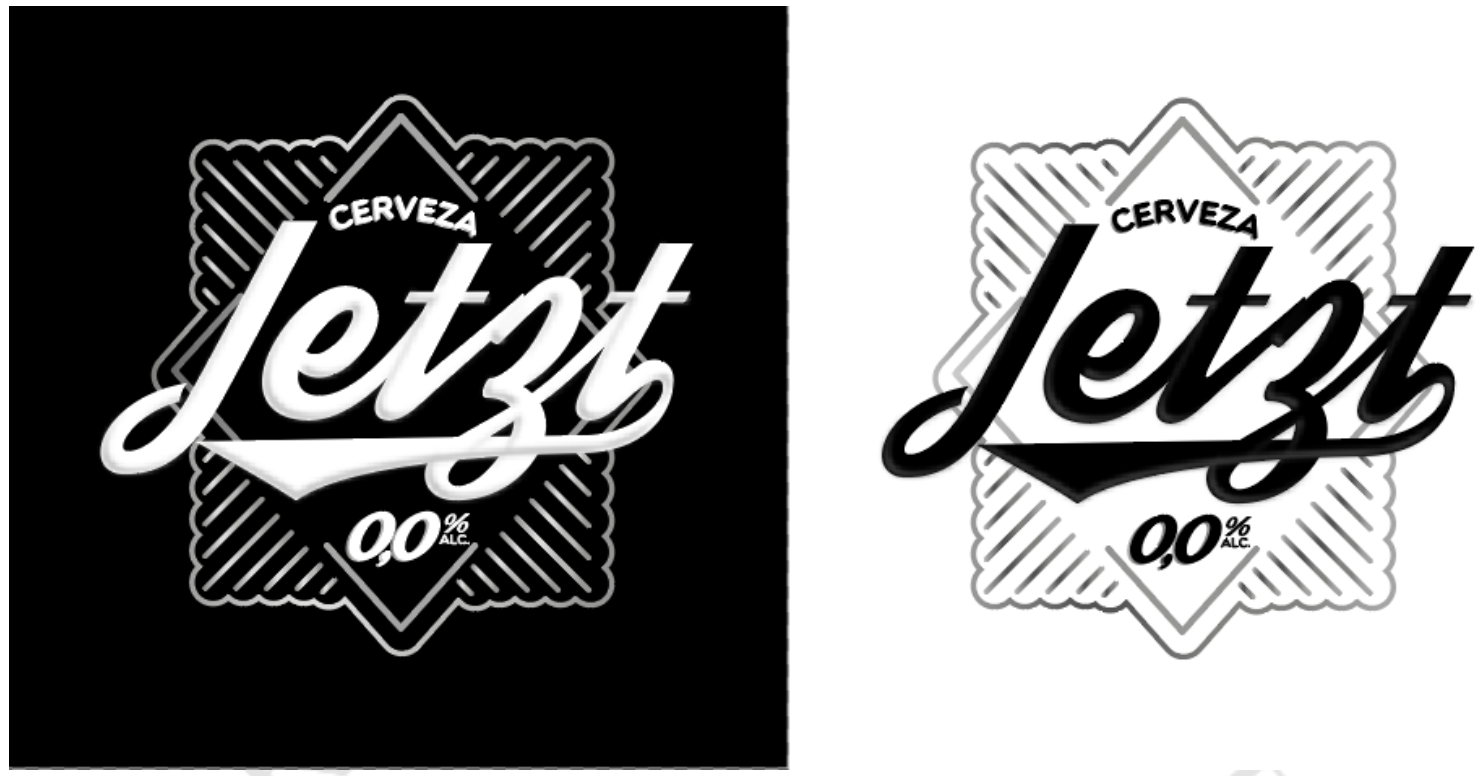

\subsubsection{Uso incorrecto del Logotipo:}

El logotipo no debe ser deformado, debe utilizarse correctamente en conjunto con la distribución y colores seleccionados, ya que debe ir coherente con la imagen de marca que queremos reflejar de prudencia y proporción.

\begin{tabular}{|l|l|}
\hline & Sin contraste: \\
Hacer uso del logotipo sin un fondo \\
que genere contraste y profundidad \\
porque pierde la atracción y no es \\
legible \\
2 \\
$\begin{array}{l}\text { Uso incorrecto de colores: } \\
\text { Hacer uso de una gama de colores que } \\
\text { no se encuentre mapeado o sea color } \\
\text { complementario del azul o que } \\
\text { distorsione la figura del logotipo. }\end{array}$ \\
\hline
\end{tabular}




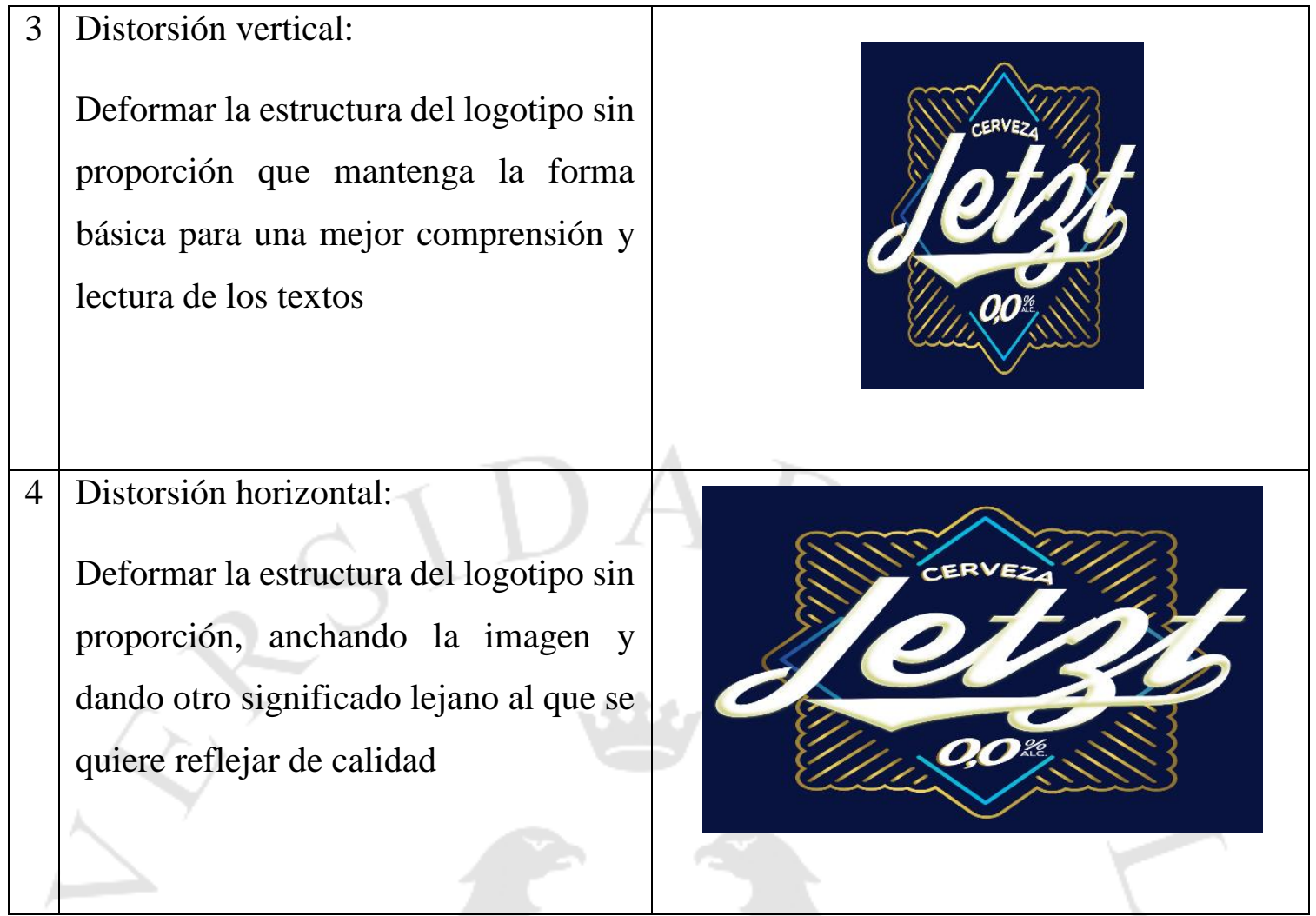

1.3 Estrategia creativa

1.3.1 Concepto creativo

Atrévete a lo distinto

\subsubsection{Idea creativa}

Se escogió "Atrévete a lo distinto" como idea fuerza de lo que se requiere que el consumidor experimente en esta campaña de lanzamiento, puntualmente "atrévete a cambiar y a buscar nuevos campos", es tiempo de incentivar esa curiosidad de ver las cosas de distinta manera a lo que ya conocen o están internamente fijado como verdad, ver desde otra perspectiva sin miedo a ser juzgado ya que se sigue manteniendo ese estigma de que la cerveza siempre es alcohol de alto porcentaje ya que este producto debe presentarse y aprovechar como una deliciosa cerveza que le brindará las bondades de una cerveza clásica con la tranquilidad de no estar ingiriendo alcohol. Para aprovechar el momento y disfrutarlo, debemos generar un cambio y este cambio se genera haciendo lo distinto, ya que nada sucederá sino se logra romper cualquier paradigma que limite. 


\subsubsection{Aplicación en el Empaque}

Con motivo de que la campaña vaya alineada a las propiedades de la marca se desarrolló los estilos de empaque que guarden relación, destacando que parte de estos empaques son propuestas con principales recomendaciones para el contenido.

\subsubsection{Empaque botella de vidrio}

La siguiente propuesta es la desarrollada para una botella de vidrio marrón de 310 $\mathrm{ml}$ de contenido, con un tamaño de $18 \mathrm{~cm}$ x $9 \mathrm{~cm}$ aproximado, esta botella cuenta con un enchapado abre fácil para poder estar alineado a los atributos de la cerveza.

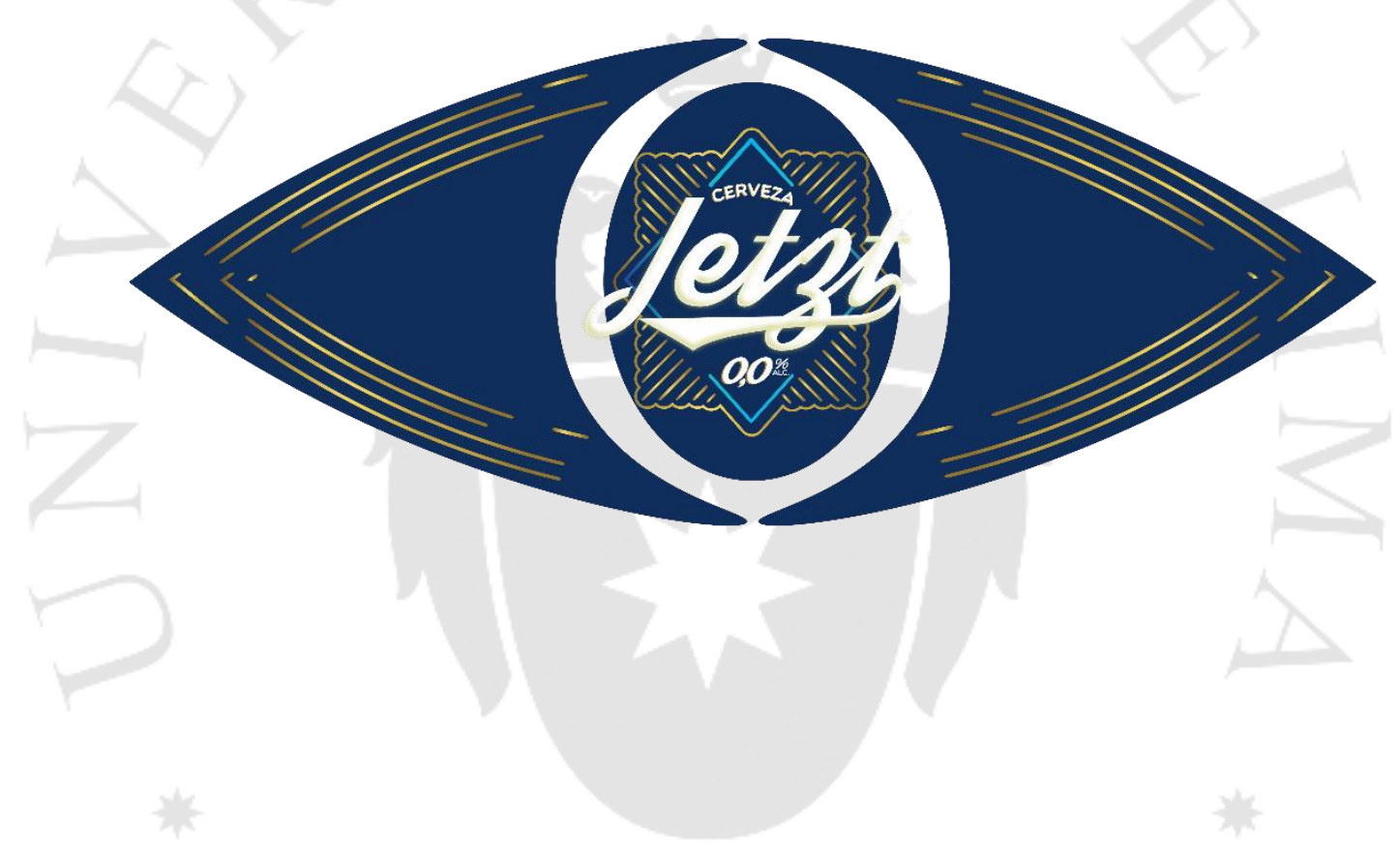



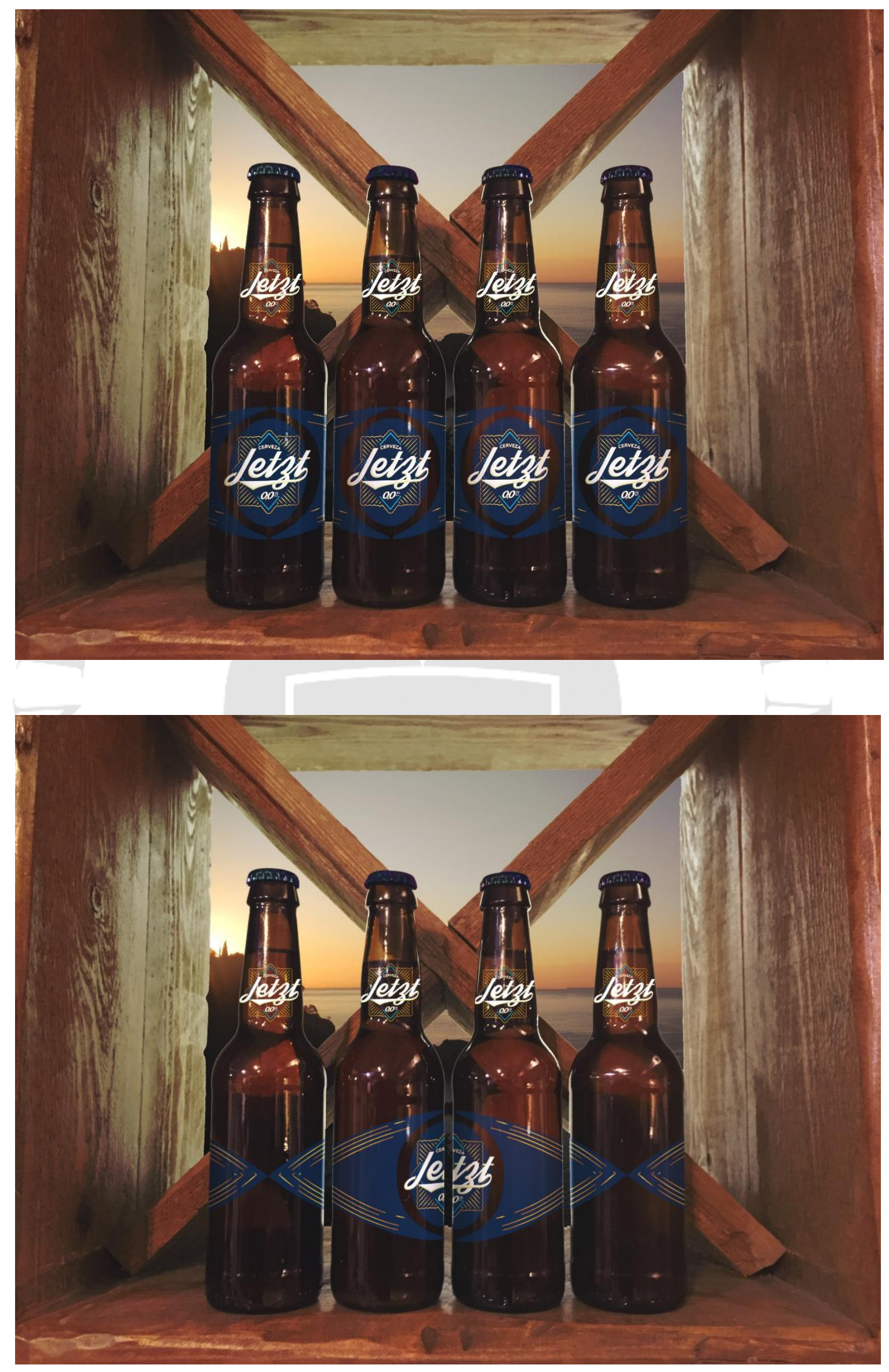
De acuerdo a la idea general de ver, hacer, actuar de manera distinta para atreverse a cambiar es que se desarrolló el empaque para la botella de vidrio. Se buscó jugar la idea fuerza de "mirarlo distinto"; buscar que le den un significado más allá de la simple etiqueta informativa; es así que se desarrolló con un juego de líneas curvas y en el centro una figura ovalada recortada, que en conjunto brindan una figura como vista de un ojo humano, siendo el iris el logo y de un cero como destacado central y aspecto principal del producto cero porcentajes de alcohol. En esta propuesta no se rellenó con material informativo del destacado comercial de ingredientes nutricionales, pero está en consideración añadirse como parte de la propuesta de etiqueta al igual que el 10\% del espacio designado por ley para añadir el mensaje de tomar bebidas alcohólicas en exceso es dañino. Por último, se detallará en la parte de especificaciones el lugar de origen de la cerveza para rescatar su nivel internacional y usar en nuestro favor las preconcepciones de calidad, veracidad que reflejan las cervezas alemanas, así mismo se contará con una traducción de lo que significa la marca para continuar con el hilo comunicativo de lo que queremos evocar.

\subsubsection{Empaque lata}

La siguiente propuesta es para la presentación en lata de $355 \mathrm{ml}$ de lata, el taño es de $18 \times 12 \mathrm{~cm}$ aproximado, esta versión es adaptable para otras versiones de lata en mayor contenido. 

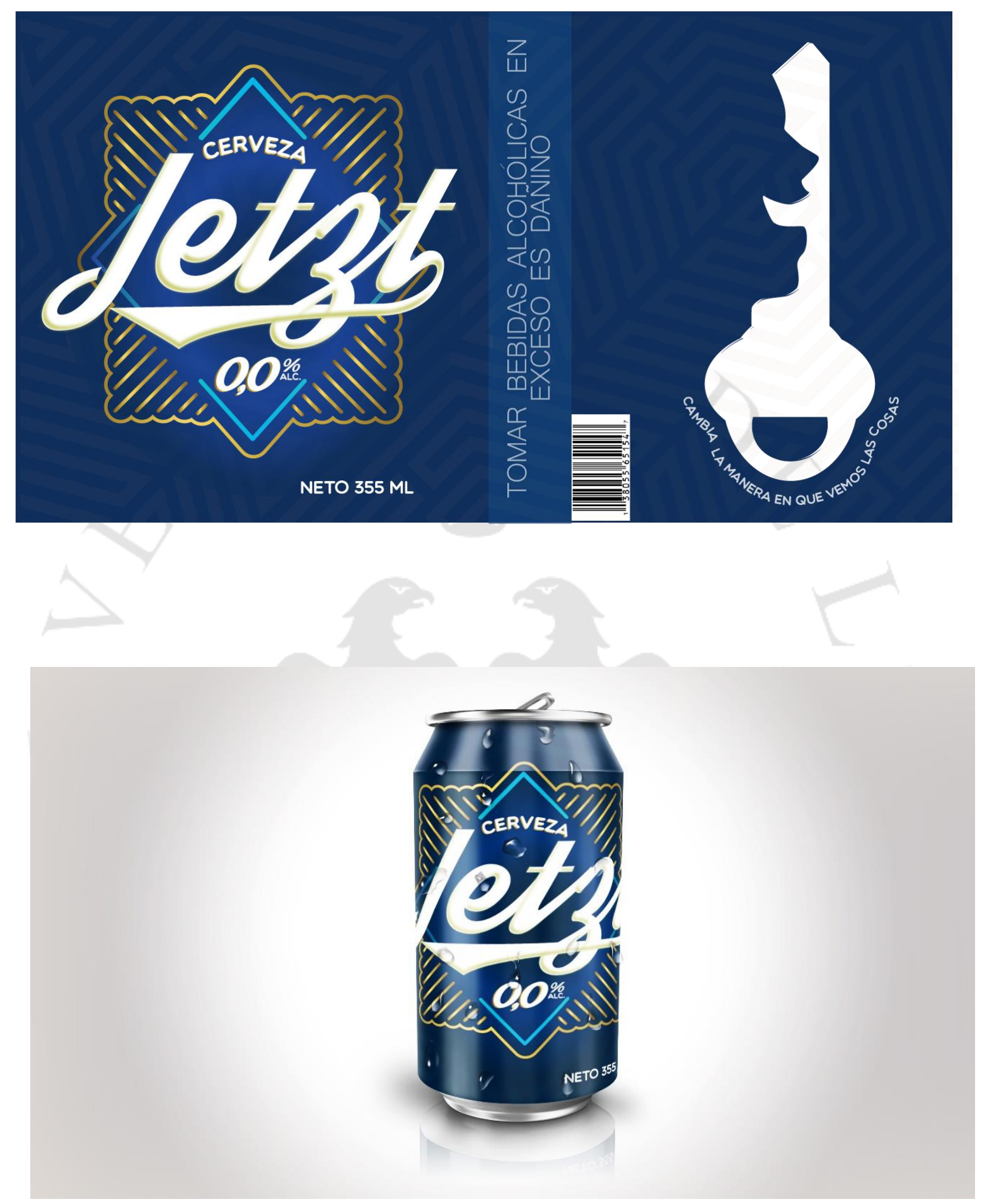


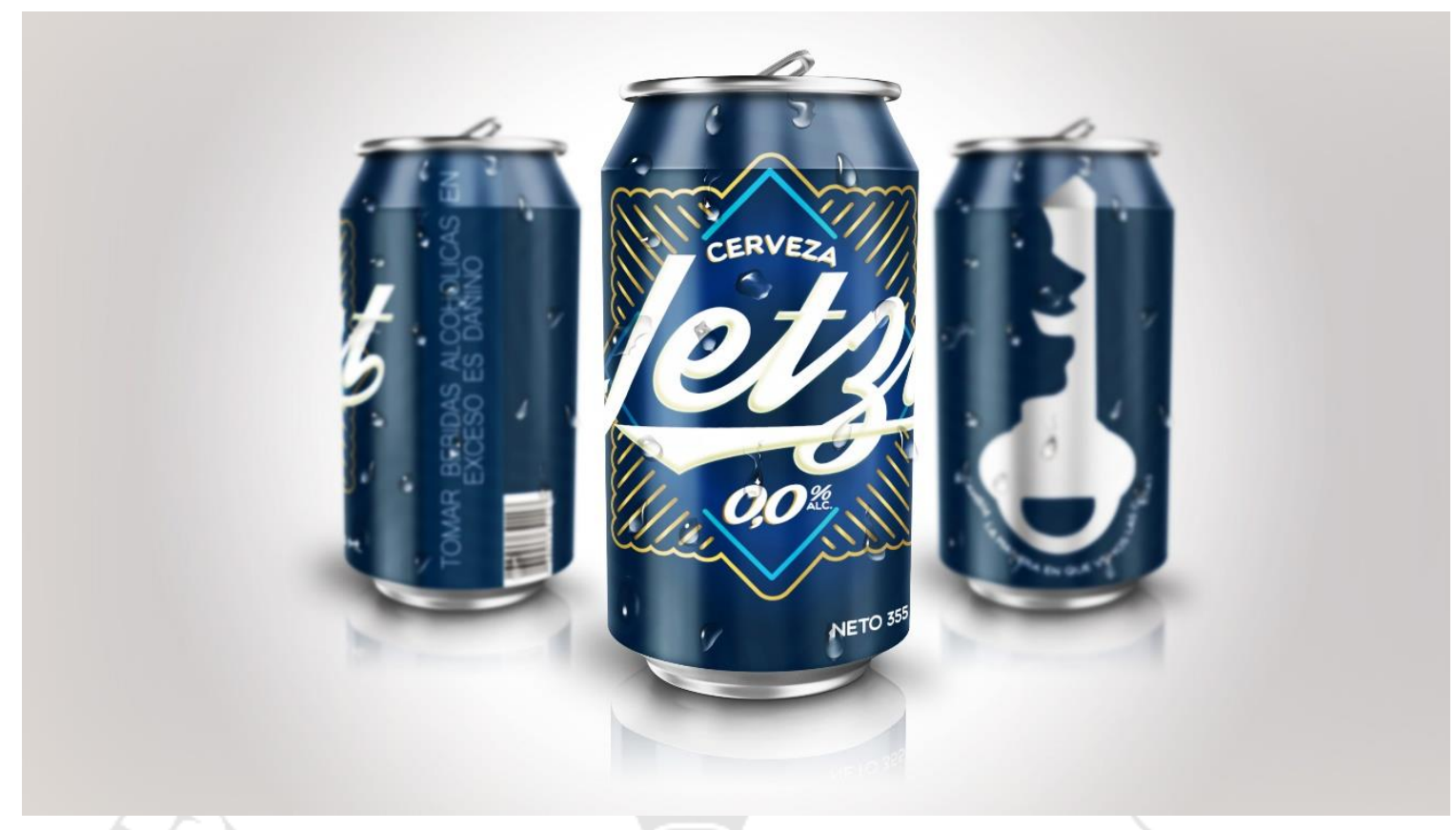

Siguiendo la línea del concepto creativo de atreverse a lo distinto, se desarrolló un empaquetado que retase la manera en cómo vemos las cosas, para ello se desarrolló una imagen que aplique la ley de Gestalt de figura y fondo, queda en la persona que observe cuál es su manera de verlo, ya que mediante esta técnica no existe una única figura e interpretación y debe animar a buscar otra perspectiva, a mirarlo de modo distinto.

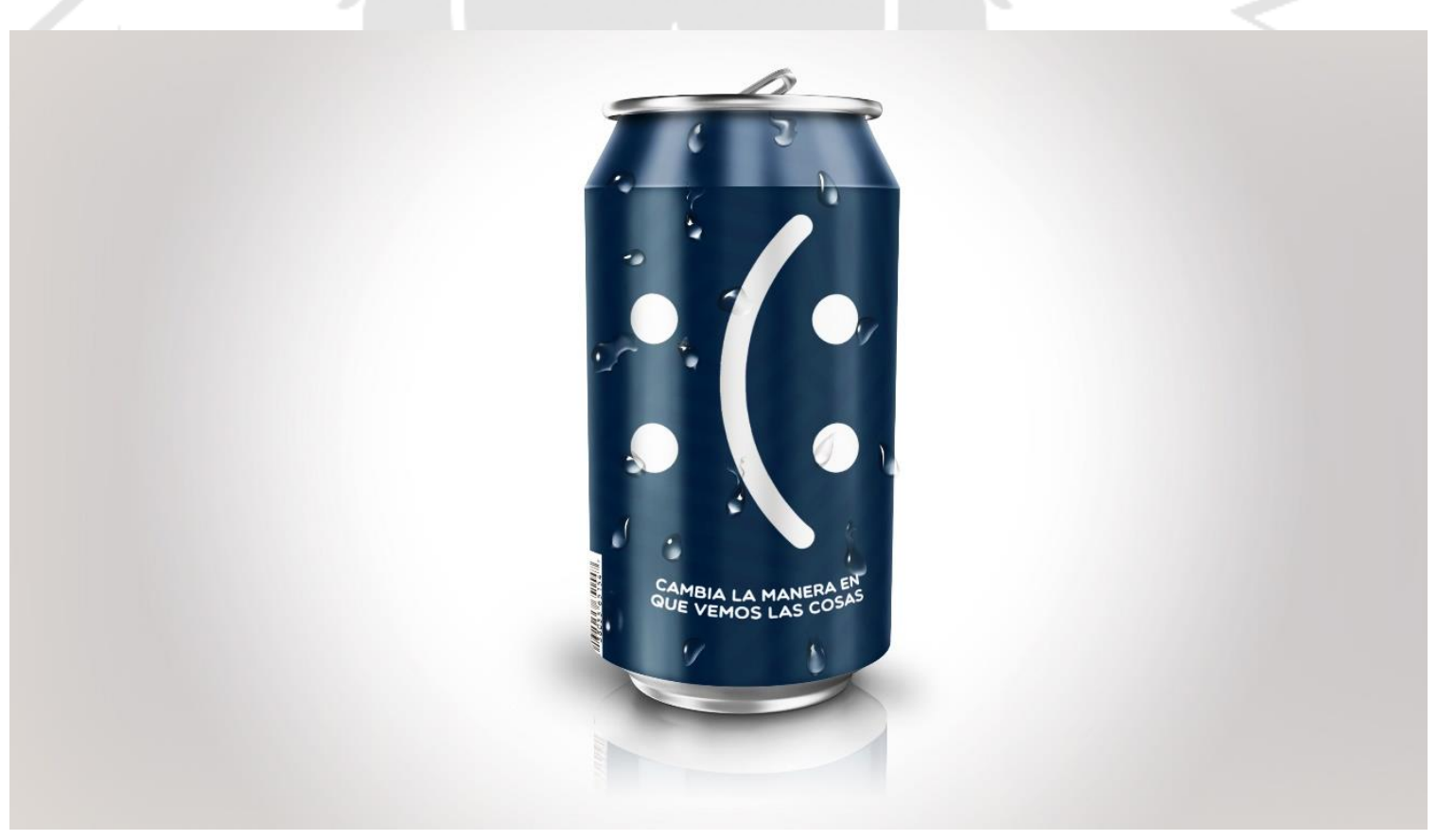




\subsection{Estrategias de Comunicación}

Para cumplir con nuestros objetivos de comunicación se decidió utilizar una campaña y trabajarla mediante "Olas" o momentos del siguiente flujo de trabajo:

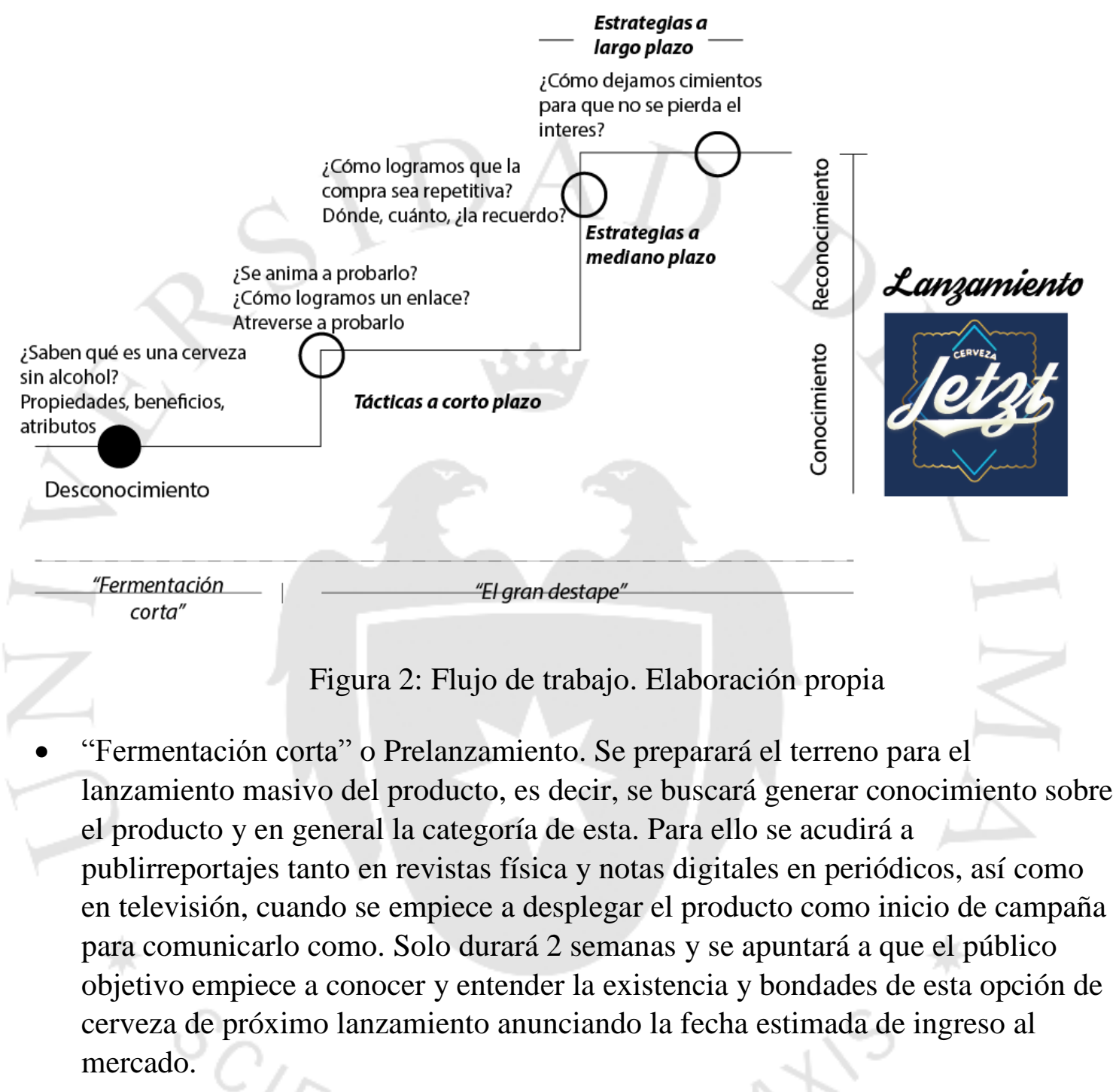

- Fase denominada "El gran destape" o Lanzamiento: Se develará el lanzamiento del producto a través de medios

- ATL: un spot de televisión, spot/espacio en radio, publicaciones en revistas comerciales y diarios para sorprender al público objetivo con el develamiento.

- En digitales se contará con publicaciones pagadas por redes sociales, así como stories de influencers del medio que vayan acorde al estilo, edad y coherencia de público para que cuenten esta nueva forma de experimentar la cerveza 
○ Las vallas publicitarias se realizarán con mayor empuje en la temporada de verano para la Costa, y en avenidas principales de Lima donde circula el público asignado, las activaciones BTL en supermercados se realizará desde el inicio de la campaña para generar un espacio de degustación y corroboración del sabor, calidad y frescura. De igual manera, para una estrategia directa al consumidor se publicará en las revistas de supermercados la ubicación y precio.

Según el análisis que ser realizó del público objetivo y considerando el presupuesto de la marca, se decidió repartir la inversión en medios de la siguiente forma:

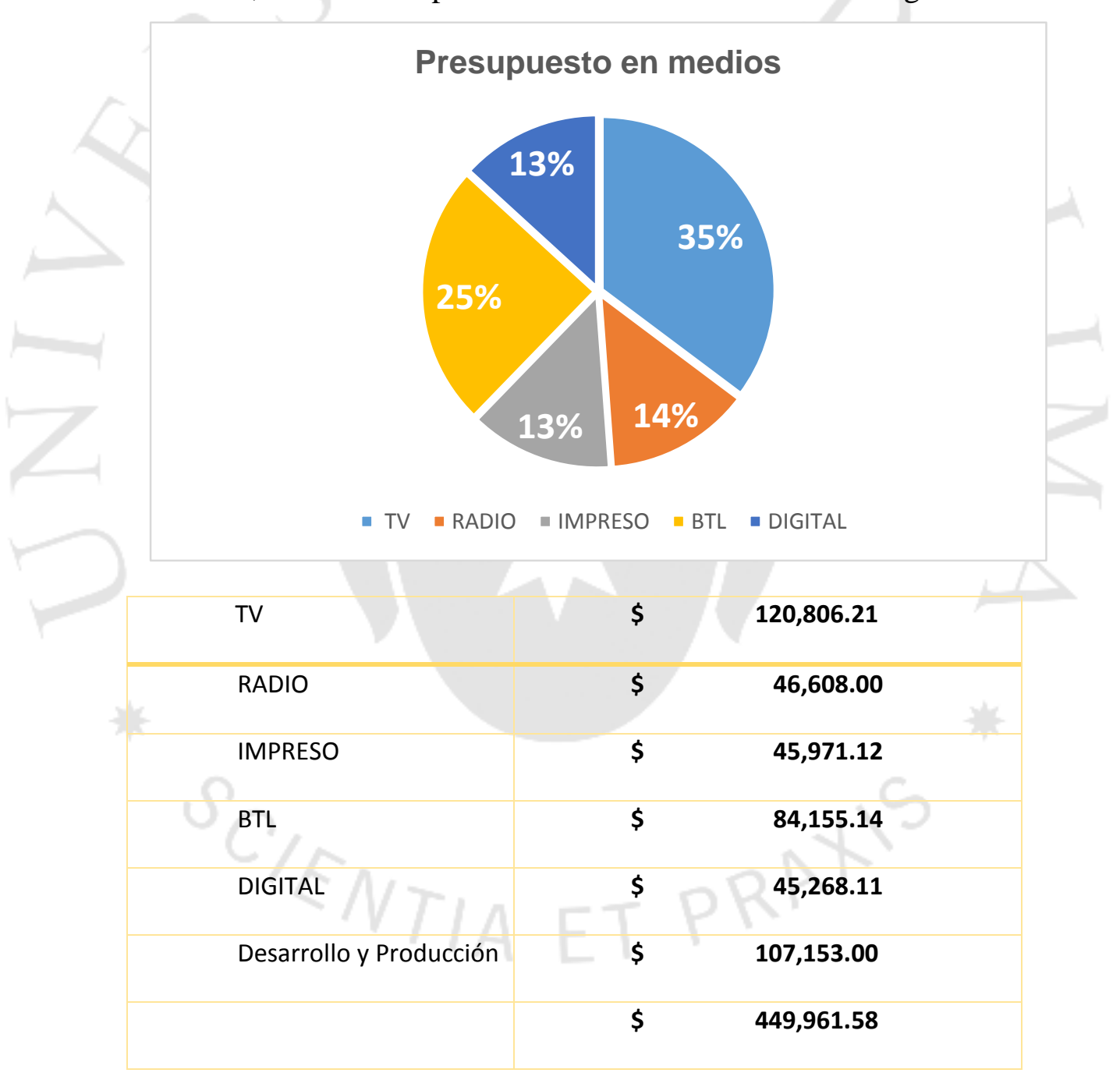




\subsubsection{Televisión}

Se eligió la televisión como uno de los medios por dónde comunicar y resonar el mensaje de lanzamiento de Jetzt ya que es un lanzamiento más allá de Lima, involucra a parte de la costa como primera Ola de ingreso comercial. El público objetivo delimitado tiene una preferencia por los canales: América y Latina, como se pudo ver en la descripción de este, así mismo se realizó la elección de los programas por factores como: rating y contenido acorde con el público.

Prelanzamiento: En esta etapa con los medios es hacer notar sobre la existencia de las cervezas sin alcohol en general y la llegada de este producto, como las grandes ciudades europeas, al Perú. Enfoque a los beneficios emocionales de libertad, confianza y seguridad de poder beberlo. El Presupuesto destinado para estas intervenciones es de \$ 9,197.66 dólares, la producción de los contenidos destinados lo realizan la casa televisiva ya que son reportajes elaborados.

\section{América:}

○ Domingo al día (D) 8:30 am a 11 am. Se eligió este noticiero dominical porque el tono de esta fase de pre lanzamiento es alistar el campo informativo, se debe realizar un pequeño reportaje pagado sobre el consumo de cervezas y la diferencia con el producto de cervezas sin alcohol, impulsando que es una tendencia en Europa su consumo, qué beneficios te brinda, el sabor similar a una cerveza tradicional y anunciado como publirreportaje en la parte final de la edición de este contenido que se acerca el lanzamiento de Jetzt cero.

○ $\quad$ Banda del Chino (LMMJV) 11:30 pm a 12:30 pm Este Magazine apunta a un público más amplio en cuanto a edad, ya que tocan temas de actualidad y novedades con un tono más jovial y divertido. Se trabajará un publirreportaje pagado con el objetivo de comunicar que la diversión con las cervezas sin alcohol nunca termina, además del consumo responsable, saludable y los beneficios que esta brinda. Finalmente resaltar quiénes en el mundo, figuras internacionales, ya la consumen y que pronto llegará al Perú. 


\section{Latina:}

- Domingo al día (D) 8:30 am a 11 am. Como segundo noticiero dominical se eligió para finalizar la semana de prelanzamiento se anuncie que desde mañana Jetzt llega al Perú, con la cerveza cero alcohol e impulsando su sabor con una prueba de sabor que garantice. Como parte final del mensaje, se enfocará a resaltar que las cervezas sin alcohol existen y son una tendencia en Europa, que se atrevan a vivir esta experiencia distinta con la cerveza.

Lanzamiento: En esta etapa durante 2 semanas, desde el 5 de noviembre, se desplegará en TV spots de 30 segundos y una tercera semana de refuerzo de spot de 10 segundos, reforzarlo con mensajes derivando al público el contacto en redes sociales. El enfoque de estos spots es comunicar el valor de la marca, la personalidad divertida y resaltar el nombre para una mejor recordación. El presupuesto destinado para las tres semanas de Lanzamiento en televisión nacional es de \$120,806.21 sin contar con la producción de los spots.

\section{América TV}

○ De vuelta al barrio (D) 8:30 pm a 9:30 pm, es uno de los programas de mayor sintonía a nivel nacional, parte de su elenco son influencers en redes sociales y vincular su imagen con el éxito de la serie logrará que refuerce el conocimiento de la marca.

○ La banda del Chino: (LMMJV) 11:30 pm a 12:30 tiene como figura principal a Aldo miyashiro.

○ Gisela EGS (S) 09:00 pm a 11:00 pm se realizará mención dentro del bloque de presentación de bailes o pausas del bloque. 


\section{Spots para América:}

1. Para el caso De vuelta al Barrio se utilizará como imagen a dos personajes de la serie que representan a personajes mayores de edad, Alejandro y Sofia para el spot dentro de la tanda comercial. Estos personajes se encuentran en la ficción del tiempo que representa la serie de los 70’s para romper esta burbuja de tiempo con el consumo de Jetzt en la playa divirtiéndose y con el hilo del mensaje de atreverse a hacer lo distinto, incluso de ir al "futuro" consumiendo este producto.

\section{- $\quad$ Duración: 30” seg}

- Días al aire: lunes - miércoles y viernes, desde el 5 de noviembre

- Música: Divertida de la época de los 70’s y cambio a música divertida actual

2. Para el caso La Banda del Chino se utilizará la imagen de Aldo Miyashiro en un spot de 30 segundos, en el cuál se encuentra jugando un partido con amigos, finalizando saca su cábala que es su cerveza, un amigo de la ficción se sorprende para luego mostrarle que es un Jetzt. El foco del mensaje es reforzar el consumo en cualquier momento que lo haga distinto al común, así como sus atributos positivos y sabor ideal.

Duración: 30" seg

- Días al aire: martes - miércoles y jueves, desde el 6 de noviembre

- $\quad$ Música: Alegre con efectos de sonido que enfaticen acciones.

\section{Latina}

- Yo soy (LMMJV) 9:30pm a 11:00 pm es un programa de imitación que tiene 4 jurados y 2 co-conductores, la temática del programa es que cada participante demuestre cuánto se parece su voz a la del artista que han escogido. Para el caso de un programa concurso se realizará una mención y dentro de la secuencia y banner. Parte de la propuesta del mensaje en la secuencia es que estén por presentar al siguiente artista en escena, pero el 
conductor se encuentra bebiendo una Jetzt cero alcohol, resaltando el agradable sabor, los beneficios y la idea fuerza de "como él" cualquier momento puedes hacer algo distinto.

- La Previa del Show (LMMJVD) desde las 11:30 a 12:30 es un programa deportivo con segmentos de entretenimiento y viendo al deporte con comicidad, resaltando lo mejor de la fecha de futbol tanto de campeonato local como internacional. La propuesta para este programa es armar un spot con el personaje principal, Jesus arias.

\section{Spot para Latina:}

1. Para el caso La Previa del Show se utilizará como imagen a Jesus Arias narrador y comentarista deportivo. Este personaje se encuentra definiendo "un partido", junto a un compañero narrador de ficción. Parte de la propuesta del mensaje es realizar la analogía del partido con la llegada de Jetzt cero alcohol, resaltando sus beneficios y que beberla en cualquier momento para hacer lo distinto es un gol.

- Duración: 30” seg

- Días al aire: lunes, jueves y domingo desde el 5 de noviembre. Son fechas de mayor índice de rating ya que cuentan con repeticiones o lo mejor de la fecha del torneo nacional.

- Música: Divertida con sonidos de audiencia de estadio, efectos de sonido que enfaticen acciones.

Cable: Para el caso de TV de cable Movistar solo se utilizará estos tres programas, en el cual aparecerá un banner de la marca en la tanda comercial. No se realizará spots especiales por conductor.

5 Destinos: Un programa que demuestran cinco alternativas para un mismo tipo de viaje, la temática ofrece actividades y sugerencias de diversión. Lo conduce Pedro Pablo Corpancho 
- Wantan Night: Un programa de entrevistas dinámicas con invitados mediáticos nacionales e internacionales, parte de la secuencia es descubrir las facetas distintas y poco conocidas de sus invitados. Lo conduce Carlos Carlin

\subsubsection{Radio}

Se decidió pautear de lunes a sábado, a pesar de no ser el medio principal de nuestro público delimitado, es uno de los medios más tradicionales, de mayor cobertura y de uso ocasional. Para el caso de los limeños el $44 \%$ escucha radio desde sus smartphones ${ }^{13}$ y hay una coexistencia entre la radio y su soporte digital de los Se eligieron las siguientes emisoras que son las más sintonizadas por nuestro público objetivo ${ }^{14}$ :

- Radio programas del Perú: Siendo el medio principal de los NSE A, B, C de 26 años a más.

- Onda Cero: Radio juvenil de mayor audiencia entre 17 a 25 años

- Oxigeno: Emisora preferida por un segmento joven de NSE AB y C, de contenido de rock/pop en ingles del recuerdo

- Planeta 107.7 Especializada en pop/rock actual, con mayor adhesión en los NSE A y B

Spots:

El spot de lanzamiento de Jetzt cero alcohol será con un mix de música, donde una misma canción, de alta referencia, en diferentes versiones como latin, balada y rock, que suene de manera disruptiva al estilo que uno conoce de la canción para dar el mensaje que lo distinto es bueno. El objetivo por reforzar es que los matices, ritmos u otros de la canción pueden cambiar, pero la esencia de la letra es la que se mantiene, y para finalizar el anuncio un mensaje que anime a probar lo distinto ya que existe un mundo por descubrir.

- Duración: 30" c/u

- Número de avisos totales: 140

- Días al aire: a partir del 5 de noviembre al 1 de diciembre

- Semana de lanzamiento: 2 semanas

- Semana de refuerzo con menos cantidad de avisos en pauta: 2 semanas

- Inversión total $\$ 46,608$ por las 4 semanas

13 Gestion. (2018, 16 abril). ¿Cuántas horas escuchan radio los peruanos? Recuperado de https://gestion.pe/tendencias/horas-escuchan-radio-peruanos-231412

${ }^{14}$ CPI. (2016). Audiencias Radiales 2016. Recuperado de https://www.cpi.pe/images/upload/paginaweb/archivo/26/mr_resumen_anual_audiencia_radial_2016.pdf 


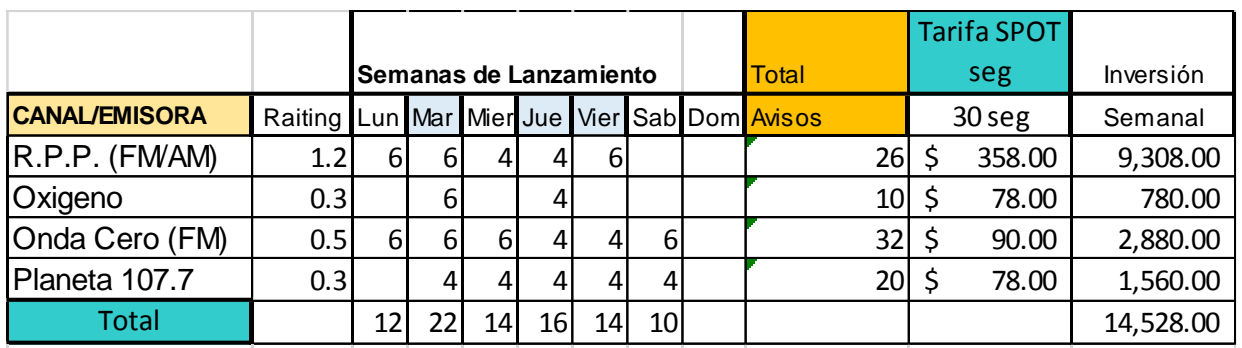

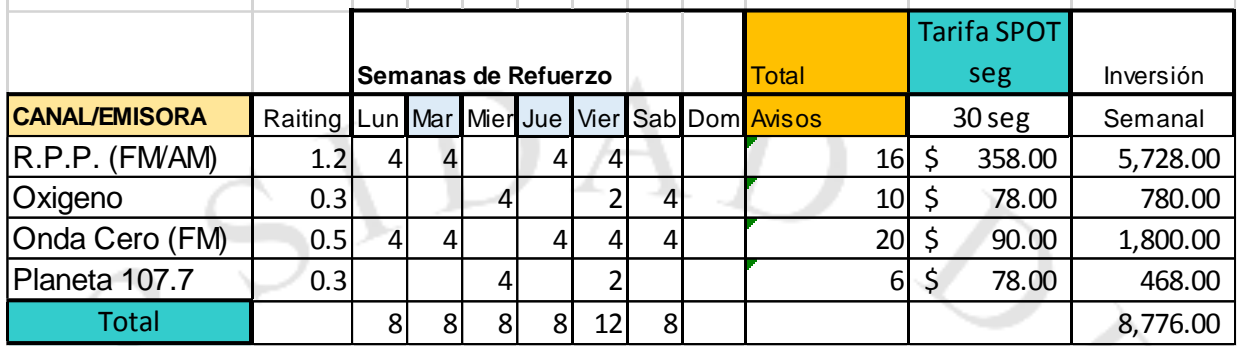

\begin{tabular}{|c|c|r|r|}
\hline RADIO & \#Semanas & Inversión semana & Inversión total \\
\hline Lanzamiento & 2 & $14,528.00$ & $\mathbf{2 9 , 0 5 6 . 0 0}$ \\
\hline Refuerzo & 2 & $8,776.00$ & $\mathbf{1 7 , 5 5 2 . 0 0}$ \\
\hline
\end{tabular}

$46,608.00$

\subsubsection{Impreso:}

\section{○ Diarios}

En este medio se utilizarán solo 3 publicaciones en el diario físico en la primera y segunda semana de la campaña de lanzamiento ya que las versiones digitales son las que tiene mayor llegada al público objetivo. Los diarios ${ }^{15}$ seleccionados son:

- El Comercio ya que es preferido por los sectores A y B, el formato es berlinés y el público objetivo de mayor frecuencia de este diario son Hombres y Mujeres de 26 años a más. Su contenido es percibido con valores como seriedad, modernidad y contenido

- El diario Perú 21 es el diario considerado "moderno", su público son hombres y mujeres de 18 años a 49 de edad de NSE AB. Tiene valores positivos como las secciones variadas y utilitarias que conectan con el estilo de vida del público y un lenguaje mucho más directo, acorde con el tiempo del público

15 ECO Media. (2016). Tarifario Actualización El Comercio 2016. Recuperado de http://e.gec.pe/67/doc/0/0/7/4/7/747497.pdf 
- Publimetro es un diario gratuito de alta afluencia en varios puntos de la ciudad donde generan activaciones en sus puntos de venta, tiene mayor afinidad con el público de hombres y mujeres de 18 a 37 años del NSE AB. Sus valores positivos y de refuerzo son el enfoque optimista y amigable con que tocan las noticias nacionales e internacionales, con formato moderno y resumido.

Publicaciones:

- Número de avisos totales: 3

- Días de publicación: lunes 5 de noviembre en Publimetro, miércoles 7 de noviembre en El Comercio y viernes 9 de noviembre en Perú 21

- Concepto del Banner: Se utilizarán imágenes que fomenten relieve, como si estuviese saliendo la noticia del diario para terminar el mensaje con el concepto de atreverse a lo distinto, en este caso el enfoque es verlo distinto y jugar con la mirada al común de los periódicos.

- Detalle de tamaños: Se adjunta Excel con la programación y tamaños

\section{○ Revistas}

Se utilizará solo dos publicaciones en la revista Somos, una será en la etapa de Prelanzamiento y la siguiente en la semana del Lanzamiento del producto al mercado. Con respecto a la semana de Pre Lanzamiento el diseño de esta publicación debe tener como foco a resaltar la tendencia y moda que se va a convertir el consumo de cerveza sin alcohol en todo momento, de crear o aprovechar nuevos momentos para poder celebrar con una cerveza y tener el bienestar de no cometer excesos. En cuanto a la semana de Lanzamiento se utilizará una gráfica de cara completa que sea más comercial y resaltando los canales donde pueden encontrar mayor información sobre el producto como Facebook, Instagram, además de tener un estilo que guarde relación con la personalidad alegre, desenfadada y fresca,

\section{Sobre la revista:}

- Somos: Tiene mayor afinidad con un público NSE AB para hombres y mujeres, pero de mayor tendencia (59\%) mujeres, su publicación es sabatina y es gratuita junto a la compra del diario el Comercio. Su diagramación, colores y fotografías son de alta calidad y cubren temas para todas las edades, intereses y géneros. 
- Número de avisos totales: 2

- Días de publicación: sábado 3 de noviembre y 10 de noviembre

- Concepto del Banner: PreLanzamiento, dar a conocer sobre el producto, resaltar la tendencia que se vive en Europa que este producto se está convirtiendo en un predilecto para cualquier momento de diversión. Lanzamiento, evocar al público a animarse a consumir lo distinto y resaltar la actitud alegre y divertida.

\subsubsection{BTL}

Las acciones BTL ayudarán a tener un contacto más cercano con el público objetivo y aportará a generar mayor conocimiento sobre el producto y recordación que genere impacto.

- Activación en Supermercados: Se contarán con presencia de impulsadoras en 12 supermercados seleccionados en La Molina, Surco, Miraflores, San Isidro, Barranco para Wong y Vivanda en el ingreso de la sección de cervezas. El concepto de esta estrategia es motivar este primer acercamiento y animar a probarlo para que despeje de dudas sobre el sabor, contenido u otro.

Tiempo: 1 mes de lanzamiento

a) Cimiento para el mantenimiento: Grabación de diferentes personas que prueben la cerveza en el punto de venta, el estilo de cámara oculta ayudará a tener mayor tráfico en las redes sociales donde se comparta esta iniciativa positiva y primer acercamiento con el producto de personas comunes.

○ Floor Graphic en Supermercados: Una forma para atraer la atención y comunicar sobre Jetzt será mediante figuras utilizará en distintas zonas del supermercado que generen tráfico y lleven a la persona a la zona de cervezas.

El concepto es en los pasillos de mayor iluminación como las zonas de verduras, carnes u otro se coloque un sticker de sombra en negro degradado de una persona bebiendo una Jetzt, a full color, con una pregunta bordeando que anime a la curiosidad, como propuesta podría incluirse una interrogante “¿Te gustaría hacer algo distinto?” "En este momento podrías estar bebiendo una Jetzt" 


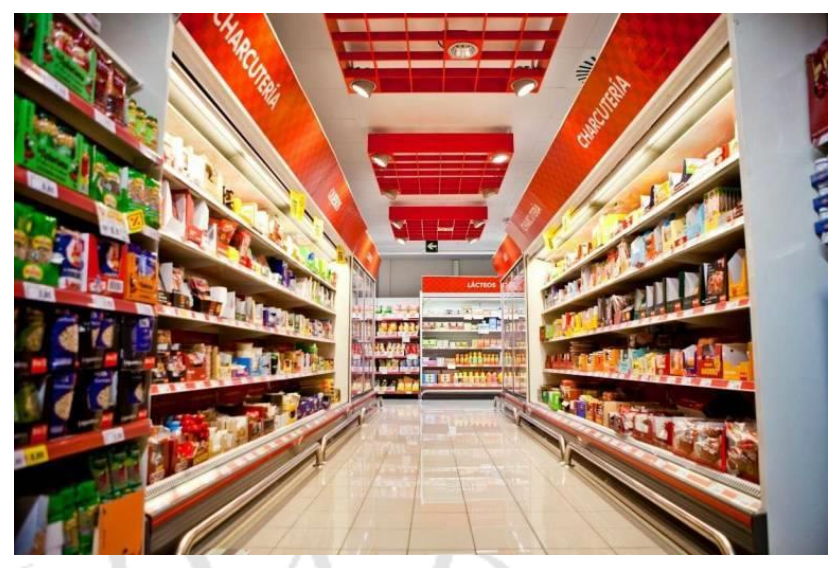

Figura 3: Imagen de referencia de zona iluminada

- Vallas Publicitarias: Se realizará 8 diseños y elaboración de vallas publicitarias. El alquiler de la estructura de las vallas estará ubicado en las zonas de tránsito de nuestro como Golf de los Incas, Raul Ferrero, San Borja norte, Canaval y Moreyra entre otros. El concepto de esta valla publicitaria es alineado a las comunicaciones en medios tradicionales, solo que invita a salir del ritmo de imagen habitual de las vallas enmarcadas, ya que se separará la figura central de la cerveza para colocarlo en otra ubicación distinta a la central.

○ Puntos de venta - Autoservicios, Listo y Tambo: Se desarrollará 50 módulos de exhibición que se distribuirán en los grifos, en los tambos de La Molina, Surco, Miraflores, San Isidro, Barranco, así como los que se encuentran aledaños a universidades. Y se pegará sticker llamativos en las refrigeradoras con mensajes que propongan a utilizar ese momento para probar algo nuevo en forma de una mano que se dibujen con las palabras.

- Activación en Plazas o Centros Comerciales: Se desarrollarán 3 activaciones desde distintos puntos desde el 26 de noviembre a 15 de diciembre. Las plazas escogidas son Jockey Plaza, Boulevard de Máncora y Boulevard de Asia, esta última estará alineada al inicio de la temporada de verano en Asia y la apertura del boulevard. El concepto de esta estrategia será generar un punto de diversión dentro del tránsito del centro comercial o plaza, para ello se contará con 5 anfitriones caracterizados con la marca, animando y repartiendo merch, latas de Jetzt y volantes de los puntos de venta de Jetzt. 
a) Cimiento para el mantenimiento: Las personas que interactúen con la activación y reciban merch deberán subir en sus muros de Facebook o Instagram disfrutando de Jetzt y etiquetando a la marca en sus stories junto al HT (\#Atrévete a lo distinto), para compartirlas desde nuestras redes, generando embajadores digitales que ayuden a comunicar y ampliar el público.

\subsubsection{Digital}

Es fundamental contar con activación dentro del mundo digital, tanto en redes sociales como banners en web, ya que nuestro público objetivo es un consumidor y productor de contenidos y su principal medio por el que se comunican son los smartphone para informarse o compartir con sus amistades. Se realizará las siguientes acciones:

○ Diseño web: Tener un sitio web con información del producto, puntos de venta, contacto y redireccionamiento a las redes sociales. Para ello se publicará la existencia de la web en la fase de Pre lanzamiento, con una cuenta regresiva del ingreso de Jetzt al Perú. Este dominio será compartido como hipervínculo con las notas de prensa 2.0 gratuitas que enviemos anunciando el ingreso al mercado, así como los publirreportajes que deriven a esta web, dándole seriedad y renombre al producto nuevo. Habrá un equipo encargado de que tengamos ganancia SEO y creación, diseño y actualización de contenidos en el dominio www.jetztperu.com

- SEM Google Search: Mediante un estudio de palabras claves seleccionamos aquellas en las cuales queremos aparecer, en la propuesta de palabras se deberá encontrar: Sin alcohol, cero alcohol, cerveza para embarazadas, alcohol en dieta, tomar y manejar, entre otros que denoten la búsqueda común al inicio de campaña ya que parte de romper el desconocimiento es la búsqueda de información y comparación.

- Publirreportajes web: Se realizarán dos publirreportajes, que cuenten con el mensaje de que es un anuncio pagado, con la información sobre las 
cervezas sin alcohol, como el poder manejar y beber o que las embarazadas también pueden tomar cerveza. El enfoque de esta estrategia es la derivación a la web de Jetzt Perú a través de hipervínculos para mayor detalle así generar tráfico. Estos publirreportajes se realizarán solo por un día en el Comercio Web y Publimetro ya que este formato de solicitud solo es de tipo especial. En el caso del Comercio Web será una nota en el flujo de portada y nota interna con hipervínculos, en cuanto a Publimetro el formato es richmedia con la posibilidad de contar con video o sonido que logre una mejor interacción con el contenido.

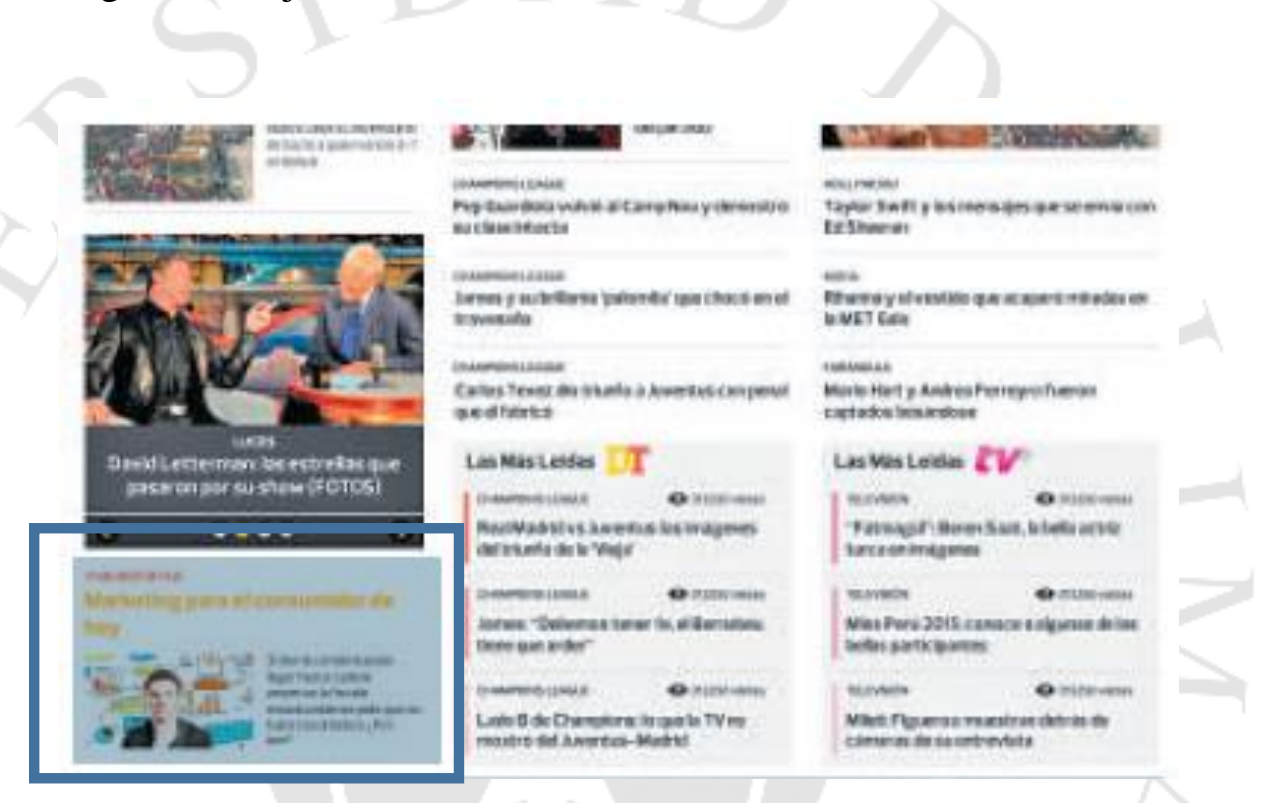

Figura de ubicación del Publirreportaje

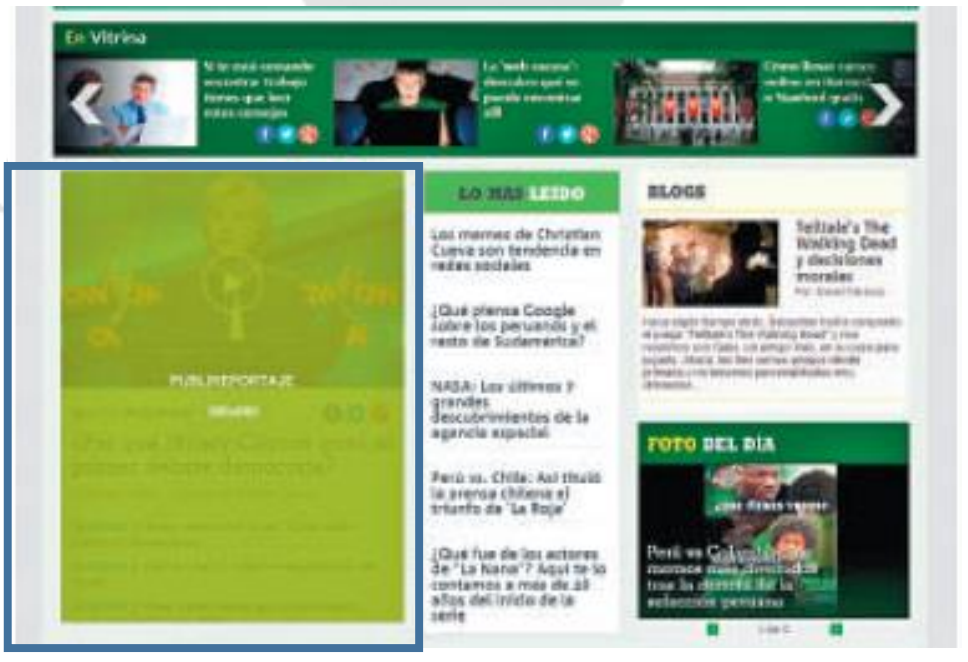

Figura de ubicación de Publirreportaje en Publimetro 
- Red display: Se utilizará la red Display de Google que nos permitirá aparecer con el formato de anuncio de marca en un conjunto de sitios web. Los formatos pueden ser de manera horizontal o vertical y deben ser anuncios que redireccionen a la web de www.jetzperu.com

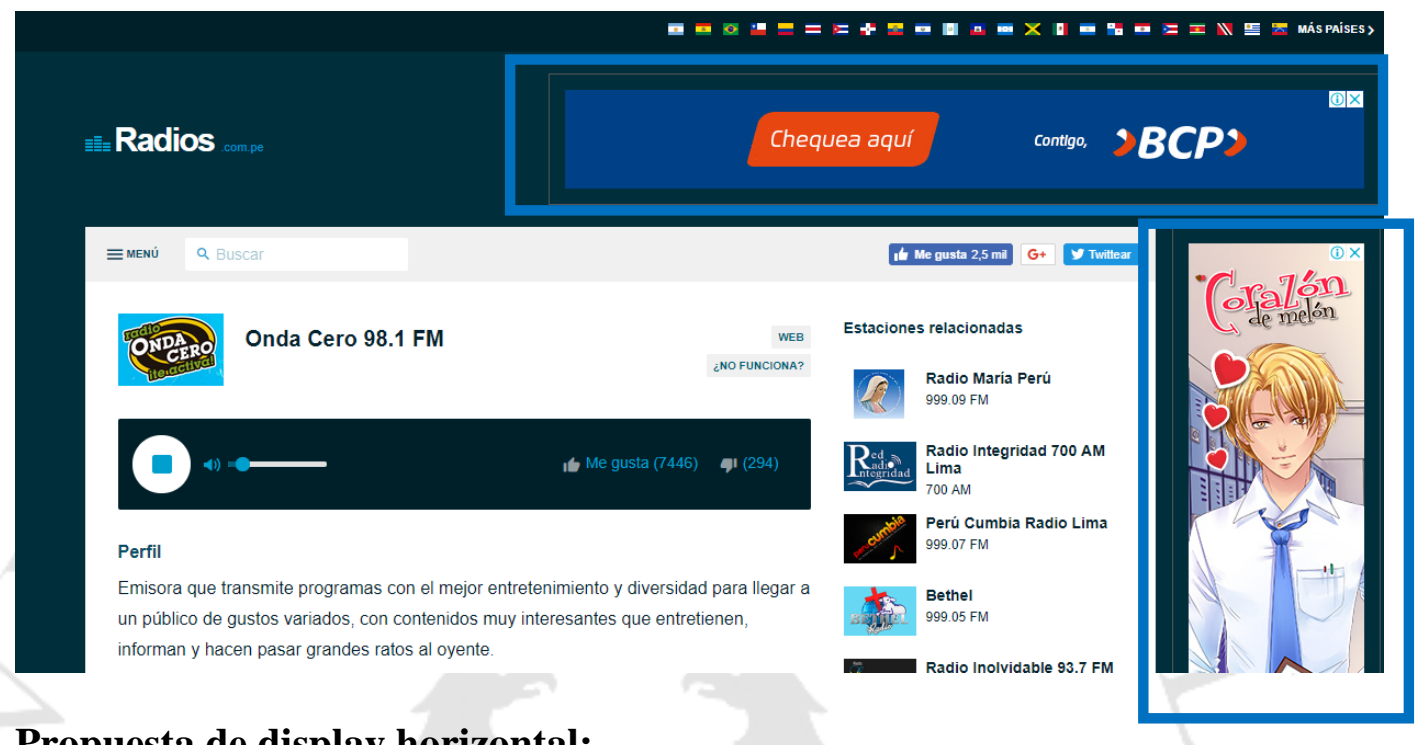

\section{Propuesta de display horizontal:}

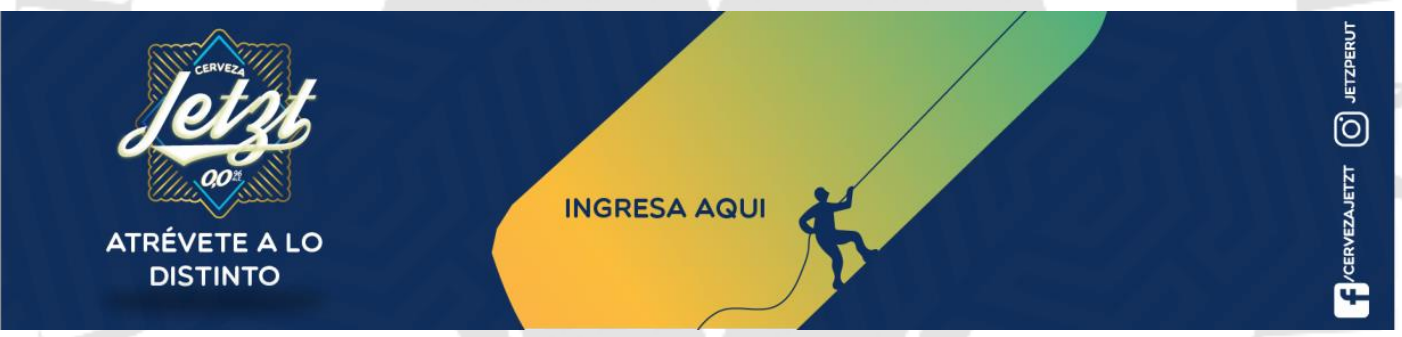

\section{$\bigcirc \quad$ Facebook ads}

Se realizará, paralelo al diseño y despliegue del la web, la página de Facebook empresa de Cerveza Jetzt Perú, el cual tendrá información sobre la marca, redirección a la web www.jetztperu.com. El estilo de la página de Facebook, al igual que el lenguaje pauteado y protocolar del Community Mannager, deben ser coloquiales y que reflejen alegría y diversión. A lo largo de 6 semanas de duración de la campaña de Facebook ads se realizará posteos diarios de Facebook. Para estos posteos nos basamos en 4 pilares principalmente:

-Gammification y sorteos: Dentro del calendario de posteos de Facebook se destinará los días jueves y domingo en el cual subiremos juegos mentales que cuestionen desde lógicas, percepciones/ópticos o laberintos que permitan interactuar a las personas con el nivel de respuestas o compartidos. Se utiliza esta herramienta por el nivel de 
competencia que involucra participación y con ello también los premios que destinaremos serán de recursos internos como merch.

-Post de Promociones de Venta: Los lunes entre semanas se realizará un post de promociones para la compra en autoservicios, tambo o Listo, en el cual se desarrollará QR's momentáneos que permitan exteriorizar el uso online con el offline de los elementos que se trabajen en Facebook hacia los puntos de venta. Se designó el día lunes ya que el enfoque es cambiar los días comunes de consumo como los viernes, jueves, sábado y domingo, para ello se trabajará de la mano con las alianzas comerciales de los puntos de venta y hacerlo efectivo al cliente.

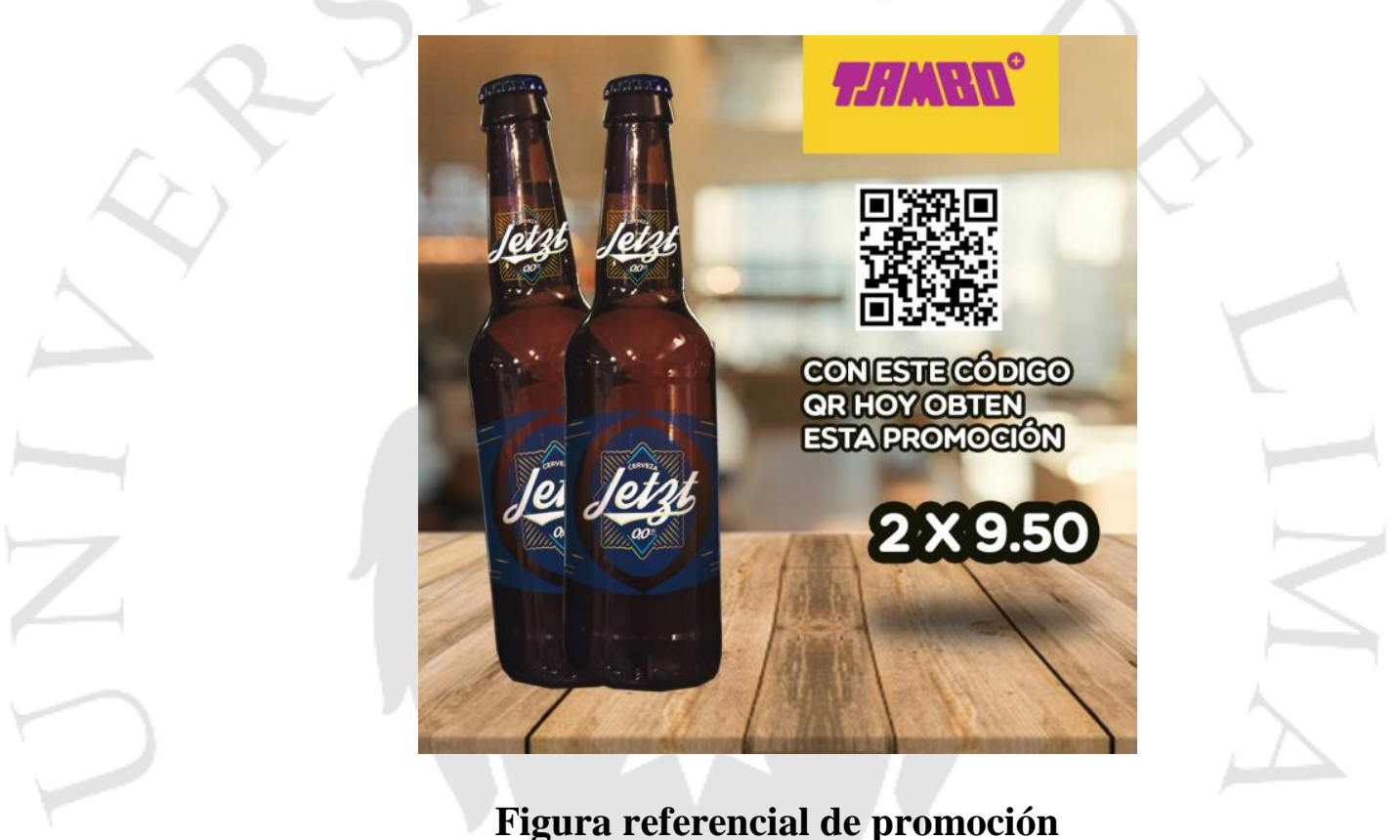

- Entretenimiento: Se colocarán fotos y videos de contenido diseñado para generar tráfico orgánico como los videos virales de las grabaciones ocultas de las degustaciones, fotos de las personas consumiendo en las activaciones, reposteo de las imágenes de Instagram de personas consumiendo y viviendo la experiencia de una cerveza distinta, por último, memes o figuras actuales que generen que el público comparta en su red de contactos.

\begin{tabular}{|c|c|c|c|c|c|c|c|}
\hline $\begin{array}{l}\text { Facebook Ads - } \\
\text { Segmentado }\end{array}$ & TOTAL & $\begin{array}{l}\text { SEMANA } \\
1\end{array}$ & $\begin{array}{l}\text { SEMANA } \\
2\end{array}$ & $\begin{array}{l}\text { SEMANA } \\
3\end{array}$ & $\begin{array}{l}\text { SEMANA } \\
4\end{array}$ & $\begin{array}{l}\text { SEMANA } \\
5\end{array}$ & $\begin{array}{l}\text { SEMANA } \\
6\end{array}$ \\
\hline Inversión & $\begin{array}{r}\$ \$ \\
12,500.00 \\
\end{array}$ & $\begin{array}{r}\$ \\
2,800.00 \\
\end{array}$ & $\begin{array}{r}\$ \\
1,400.00 \\
\end{array}$ & $\begin{array}{r}\$ \\
1,400.00 \\
\end{array}$ & $\begin{array}{r}\$ \\
2,300.00 \\
\end{array}$ & $\begin{array}{r}\$ \\
2,300.00 \\
\end{array}$ & $\begin{array}{r}\$ \\
2,300.00 \\
\end{array}$ \\
\hline Estimado diario & & 900,000 & 650,000 & 650,000 & 780,000 & 780,000 & 780,000 \\
\hline Instagram & $\begin{array}{r}\$ \\
3,900.00\end{array}$ & $\begin{array}{r}\$ \\
900.00\end{array}$ & $\begin{array}{r}\$ \\
600.00\end{array}$ & $\begin{array}{r}\$ \\
600.00\end{array}$ & $\begin{array}{r}\$ \\
600.00\end{array}$ & $\begin{array}{r}\$ \\
600.00\end{array}$ & $\begin{array}{r}\$ \\
600.00\end{array}$ \\
\hline $\begin{array}{l}\text { Creador de Contenido } \\
\text { y CM }\end{array}$ & $\begin{array}{r}\$ \\
2,700.00 \\
\end{array}$ & & & & & & \\
\hline Influencers & $\begin{array}{r}\$ \\
4,776.11 \\
\end{array}$ & & & & & & \\
\hline
\end{tabular}




\section{Instagram}

Se destinarán 3900 dólares en motivar y fortalecer esta red social con imágenes que sean producidas por la empresa como producidas por el consumidor, compartiremos historias y fotografías de las personas consumiendo, así como impulsaremos que nos compartan en un storie la historia más loca y distinta que han hecho y cómo se animaron a hacerlo, cómo se atrevieron para luego compartirlo en nuestro Instagram como un challenge con premios de merch o invitaciones, la primera semana será de 900 dólares de inversión que involucra gasto en Post de Instagram que deriven al perfil, otro que derive a la página cuando se trate de un post de puntos de venta, Stories y destacados del público y figuras televisivas. El foco de esta red es generar un lazo mucho más amical que informativo, así el consumidor puede entablar una mejor relación con la marca, para llegar a más personas en la campaña de lanzamiento y de redes se destinará 4776.11 dólares para contar con 5 influencers 2 varones y 3 mujeres, que cuenten con la misma actitud y potencial de influencia en el público que anime a las personas a comentar y participar de las acciones que se desarrollen. Los influencers elegidos por el estilo y actitud son Luciano Mazzetti, cheff internacional que comparte en sus redes las aventuras que tiene al descubrir la gastronomía y aventuras de otros países y el nuestro, Fatima y Daniela de misias pero viajeras, Alejandra Chavez influencer bloggera de Lima Saludable y por último Mateo Garrido Lecca, comediante de stand up y locutor radial.

\section{CONCLUSIONES}

- La idea de marca, derivada de la visión de marca, es "Aprovecha el momento para hacer algo distinto" que ayudará a futuras campañas publicitarias pues destaca las ventajas diferenciales de la marca como son las virtudes de poder disfrutar y realizarlo, el concepto estratégico para el plan de comunicación de lanzamiento es "Atrévete a lo distinto", que ayudará a generar en las personas el ánimo y entusiasmo de probar una cerveza distinta en contenido de alcohol pero igual en sabor, frescura y calidad. 
- La marca tiene la oportunidad de que las cervezas sin alcohol se potencien con su imagen benévola para crear o animar a nuevos momentos de consumo

- La marca tiene, además, la posibilidad de verse como líder en categoría si asociamos todas las virtudes del producto con la marca.

- El factor positivo como beneficio emocional es de libertad y seguridad que te brinda la cerveza sin alcohol.

- El plan de comunicación tiene que ir de acuerdo a la Ola comercial, en esta primera tanda se lanzará a la Costa que involucra a Lima como su principal referente, seguida de Arequipa, Piura, Tumbes entre otras.

- Se utiliza los medios tradicionales, a pesar de ser un público de redes y web, porque necesitamos llegar a la mayor cantidad de impactos, sea o no el público primario quien lo utilice los tradicionales tiene mejor cobertura de espacio, además de que existe la posibilidad de traspaso de lo online a lo offline.
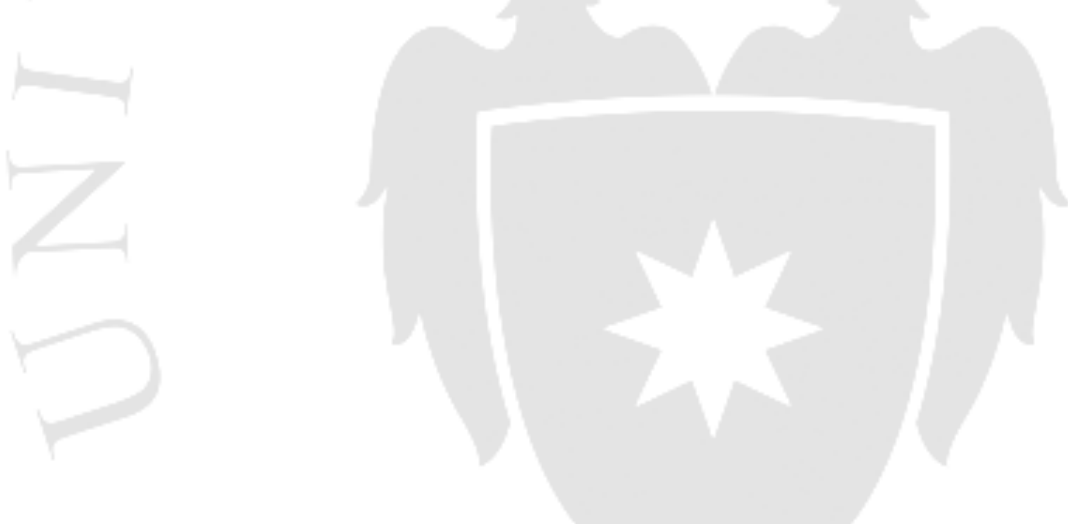

\section{RECOMENDACIONES}

- Se recomienda evaluar la posibilidad, después del lanzamiento del producto, auspiciar nuevos deportes peruanos de categoría mundial, así generamos recordación a un público que puede brindar asociaciones de las bondades de este auspiciado con las virtudes y bienestar que deseamos enviar.

- Se recomienda realizar fiestas temáticas que reflejen el espíritu de Jetzt, estos eventos logran traer tráfico de publicaciones con la marca, así podemos impulsar los valores y personalidad de marca. 
- Como parte comercial, se recomienda generar nuevas alianzas y espacios de venta de Jetzt, si bien tenemos ahora cubierto el espacio de autoservicios y góndolas en centros comerciales aún seguimos esperando a que el consumidor vaya al producto más no le damos la facilidad de acercarnos, es por ello que se debe idear como estrategia de mantenimiento, un beer truck que logre contar con todos los permisos para participar de estos eventos que se logran en parques de distintos distritos como Surco, La molina o Jesus María entre los más renombrados y acudidos. Así poder seguir asociando el consumo de la cerveza en cualquier circunstancia y lugar. 


\section{REFERENCIAS}

- IAB Perú. (s.f.). BrandZ Top 20 - Perú. Recuperado de https://iabperu.com/news/20topbrandz-peru

Chávez, L. (2018, 11 mayo). ¿Cómo afectará el alza del ISC a las bebidas alcohólicas? Recuperado de https://elcomercio.pe/economia/peru/impuesto-selectivo-consumoafectara-alza-isc-bebidas-alcoholicas-noticia-519077

CEI. (2017, 9 octubre). Psicología de las formas en el Diseño Gráfico. Recuperado de https://cei.es/psicologia-de-las-formas-en-el-diseno-grafico/

CPI. (2016). Audiencias Radiales 2016. Recuperado de https://www.cpi.pe/images/upload/paginaweb/archivo/26/mr_resumen_anual_aud iencia_radial_2016.pdf

ECO Media. (2016). Tarifario Actualización El Comercio 2016. Recuperado de http://e.gec.pe/67/doc/0/0/7/4/7/747497.pdf

Gestion. (2018, 16 abril). ¿Cuántas horas escuchan radio los peruanos? Recuperado de https://gestion.pe/tendencias/horas-escuchan-radio-peruanos-231412

Gestión. (2018, 15 febrero). LOS CAMBIOS EN LAS PREFERENCIAS DE LOS CONSUMIDORES ESTAN MODIFICANDO LA INDUSTRIA DE BEBIDAS | Blogs | Gestión. Recuperado 9 septiembre, 2018, de https://gestion.pe/blog/vinospiscosymuchomas/2018/02/los-cambios-en-laspreferencias-de-los-consumidores-estan-modificando-la-industria-debebidas.html?ref=gesr

Heller, E. (2004). Psicología del color: cómo actúan los colores sobre los sentimientos y la razón. Barcelona, España: Gustavo Gili.

Ipsos Apoyo. (2017). Medios Tradicionales: Hábitos y Actitudes . Lima : Ipsos.

Ipsos Apoyo. (2017). Perfil del Smartphonero. Lima: Ipsos.

Ipsos Apoyo. (2018). Perfil del adulto joven peruano . Lima: Ipsos Peru.

Ipsos Apoyo. (2018). Perfil del usuario de redes sociales . Lima: Ipsos Peru. 
Redacción EC. (2017, 5 agostoa). Backus y las marcas con las que domina el mercado cervecero en el Perú [FOTOS]. Recuperado 2 septiembre, 2018, de https://elcomercio.pe/economia/backus-marcas-domina-mercado-cervecero-perufotos-noticia-447675?foto $=2$

Redacción EC. (2017, 14 juliob). El 78\% de los consumidores de cerveza trata de cuidar su salud. Recuperado 9 septiembre, 2018, de https://elcomercio.pe/economia/peru/78-consumidores-cerveza-trata-cuidar-salud442287

Redacción Gestión. (2015, 15 octubre). Venta de SABMiller abre espacio para aumento de precios y nuevas marcas. Recuperado de https://gestion.pe/economia/empresas/venta-sabmiller-abre-espacio-aumentoprecios-nuevas-marcas-102493

Redacción LR. (2011, 3 febrero). Junín, Puno y Piura consumen más cerveza. Recuperado de https://larepublica.pe/archivo/516554-junin-puno-y-piura-consumen-mascerveza

SUNAT. (s.f.). Concepto del Impuesto Selectivo al Consumo. Recuperado de http://orientacion.sunat.gob.pe/index.php/empresas-menu/impuesto-general-a-lasventas-y-selectivo-al-consumo/impuesto-selectivo-al-consumo-empresas

SUTRAN. (s.f.). Reglamento nacional de tránsito | Sutran - Superintendencia de Transporte Terrestre de Personas, Carga y Mercancías. Recuperado 8 septiembre, 2018, de http://www.sutran.gob.pe/reglamento-nacional-de-transito/

Temperaturas de servicio adecuadas para cada tipo de cerveza. (2018, 15 junio). Recuperado 2 septiembre, 2018, de https://www.thebeertimes.com/temperaturasde-servicio-adecuadas-para-cada-tipo-de-cerveza 


\section{ANEXO}

- Encuestas sobre la Cerveza

Se enviará a un grupo de personas de 21 años a más que pertenezcan al NSE AB sobre el consume de cervezas para que nos brinden de primera Fuente sus apreciaciones

1). ¿Consumes Cerveza?

2). ¿Cada cuánto lo realizas?

3). ¿Qué es lo que más te gusta de la Cerveza?

4). ¿Qué es lo que menos te gusta de la Cerveza?, ¿por qué?

5). ¿Sabes de la existencia de cervezas sin alcohol?

6). Conoces alguna de estas marcas (enviar fotografía de góndola)

7). ¿Qué es lo primero que piensas cuando te digo cerveza sin alcohol?

8). ¿Qué crees lograr con una cerveza sin alcohol? ¿Qué ventajas rescatarías? 